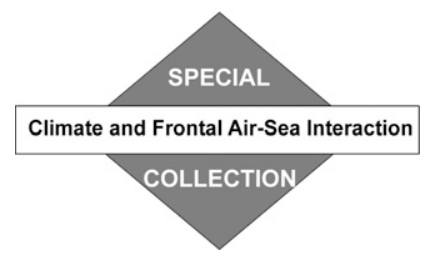

\title{
Impacts of a Midlatitude Oceanic Frontal Zone for the Baroclinic Annular Mode in the Southern Hemisphere
}

\author{
Morio Nakayama, ${ }^{\mathrm{a}}$ Hisashi Nakamura, ${ }^{\mathrm{a}, \mathrm{b}}$ AND Fumiaki Ogawa ${ }^{\mathrm{c}}$ \\ ${ }^{a}$ Research Center for Advanced Science and Technology, The University of Tokyo, Tokyo, Japan \\ ${ }^{\mathrm{b}}$ Japan Agency for Marine-Earth Science and Technology, Yokohama, Japan \\ ${ }^{\mathrm{c}}$ Department of Natural History Sciences, Graduate School of Science, Hokkaido University, Sapporo, Japan
}

(Manuscript received 16 May 2020, in final form 7 April 2021)

\begin{abstract}
As a major mode of annular variability in the Southern Hemisphere, the baroclinic annular mode (BAM) represents the pulsing of extratropical eddy activity. Focusing mainly on subweekly disturbances, this study assesses the impacts of a midlatitude oceanic frontal zone on the BAM and its dynamics through a set of "aquaplanet" atmospheric general circulation model experiments with zonally uniform sea surface temperature (SST) profiles prescribed. Though idealized, one experiment with realistic frontal SST gradient reasonably well reproduces observed BAM-associated anomalies as a manifestation of a typical life cycle of migratory baroclinic disturbances. Qualitatively, these BAM features are also simulated in the other experiment where the frontal SST gradient is removed. However, the BAM-associated variability weakens markedly and shifts equatorward, in association with the corresponding modifications in the climatological-mean storm track activity. The midlatitude oceanic frontal zone amplifies and anchors the BAM variability by restoring near-surface baroclinicity through anomalous sensible heat supply from the ocean and moisture supply to cyclones, although the BAM is essentially a manifestation of atmospheric internal dynamics. Those experiments and observations further indicate that the BAM modulates momentum flux associated with transient disturbances to induce a modest but robust meridional shift of the polar-front jet, suggesting that the BAM can help maintain the southern annular mode. They also indicate that the quasi-periodic behavior of the BAM is likely to reflect internal dynamics in which atmospheric disturbances on both subweekly and longer time scales are involved.
\end{abstract}

KEYWORDS: Atmosphere; Annular mode; Atmosphere-ocean interaction; Eddies; Storm tracks; Climate variability

\section{Introduction}

Large-scale tropospheric variability in the extratropical Southern Hemisphere (SH) is characterized by two types of annular modes. One is the southern annular mode (SAM), which represents meridional shifts of an eddy-driven polarfront jet (PFJ) (Thompson and Wallace 2000). The other is the baroclinic annular mode (BAM), which represents pulsing of extratropical eddy activity (Thompson and Woodworth 2014, hereafter TW14). The SAM is identified basically through an empirical orthogonal function (EOF) analysis applied to anomalies in zonal wind or sea level pressure (SLP) within the extratropical $\mathrm{SH}$, while the BAM is through that applied to anomalous eddy kinetic energy (EKE).

As pointed out by TW14, the SAM and BAM play different roles in the energy cycle within the extratropical troposphere. The SAM is associated with variability of both eddy momentum flux and kinetic energy (KE) of zonal-mean flow but with

\footnotetext{
¿ Denotes content that is immediately available upon publication as open access.
}

Corresponding author: Morio Nakayama, nakayama@atmos. rcast.u-tokyo.ac.jp little variability of eddy heat flux and EKE, while the opposite is the case for the BAM. From this viewpoint, the SAM is driven by barotropic processes and may thus be referred to as a "barotropic" annular mode, while the BAM is driven by baroclinic processes and therefore called a "baroclinic" annular mode. TW14 concluded that the SAM and BAM are almost decoupled. TW14 also found that the BAM is characterized by quasi-periodicity with periods of 20-30 days. Thompson and Barnes (2014, hereafter TB14) explained this periodicity using a simple model that contains a negative feedback loop between extratropical baroclinicity, poleward eddy heat flux, and radiative dumping. Wang and Nakamura $(2015,2016)$ confirmed the quasi-periodic behavior of anomalous EKE and eddy heat flux.

The extratropical energy cycle, in which the SAM and BAM are involved, is mainly related to fluxes of heat and westerly momentum associated with wavy disturbances whose characteristics depend strongly on their time scales. Blackmon (1976) and Blackmon et al. $(1977,1984)$ found that low-frequency disturbances with periods longer than about a week exhibit quasi-stationary features, which sometimes form blocking-flow configurations. They also found that high-frequency subweekly disturbances exhibit strong correspondence to migratory synopticscale baroclinic disturbances. Regions of large variance associated with high-frequency disturbances are called "storm tracks" where those baroclinic disturbances recurrently develop. 
Deepening our understanding of the dynamics of the BAM variability that manifests as the pulsing of eddy activity should be based on our understanding of mechanisms for the life cycle of baroclinic disturbances. For efficient development of baroclinic disturbances, a strong meridional temperature gradient (i.e., baroclinicity) is required, as illuminated in linear theories by Charney (1947) and Eady (1949). In recent years, Nakamura et al. (2004) and Nakamura and Shimpo (2004) suggested the importance of midlatitude oceanic frontal zones, characterized by pronounced meridional gradients of sea surface temperature (SST) as the confluence zones of warm and cool ocean currents, in maintaining surface baroclinicity for recurrent development of baroclinic disturbances. They showed a sharp contrast in heat supply from the ocean across the frontal zone allows efficient restoration of surface baroclinicity relaxed by systematic poleward heat transport associated with those disturbances. They argued that this efficient restoration could explain the observed tendency for the major storm tracks to be organized near the oceanic frontal zones. For example, the Antarctic Polar Frontal Zone (APFZ) is a circumpolar belt of strong SST gradients observed at $40^{\circ}-55^{\circ} \mathrm{S}$, and the core region of the SH storm track is collocated with the strongest SST gradient along APFZ in the south Indian Ocean (Nakamura and Shimpo 2004; Nakamura et al. 2004, 2008). Those studies also pointed out that moisture supply from a warm current along an oceanic frontal zone is important in energizing individual cyclones along the storm track.

To highlight the importance of a midlatitude oceanic frontal zone for the storm track formation, Nakamura et al. (2008) compared a pair of aquaplanet experiments with an atmospheric general circulation model (AGCM) in which two different fields of zonally uniform SST were prescribed, one with frontal SST gradients in the midlatitudes and the other without. They demonstrated that the frontal SST gradients energize baroclinic disturbances, thereby anchoring a storm track through the differential sensible heat supply across the oceanic frontal zone, referred to as "oceanic baroclinic adjustment" (Sampe et al. 2010). Its effectiveness has also been confirmed in a high-resolution coupled GCM (Nonaka et al. 2009), a regional atmospheric model (Taguchi et al. 2009), and a steady response in a planetary-wave model (Hotta and Nakamura 2011). Through aquaplanet AGCM experiments, Ogawa et al. (2012) assessed the dependence of climatological storm track activity and PFJ on the latitude of an oceanic frontal zone, while Nakamura et al. (2008) and Sampe et al. (2013) pointed out that the oceanic frontal zone is necessary for realistic reproduction of the SAM in the model. Ogawa et al. (2016) argued that the SAM is a manifestation of wobbling between the two dynamical regimes: one under the strong influence of the oceanic frontal zone and the other controlled by atmospheric internal dynamics. These studies motivate us to assess the importance of an oceanic frontal zone for the BAM variability manifested as the pulsing of storm track activity.

The purpose of this study is to assess the impacts of the oceanic frontal zone on the BAM as observed in the SH and thereby deepen our understanding of its dynamics. As in the previous studies, we analyze output data of aquaplanet AGCM experiments with zonally uniform SST profiles. In the idealized

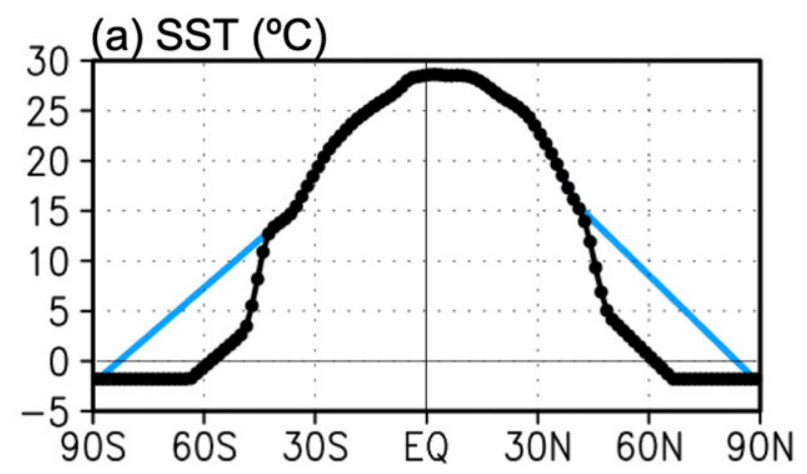

(b) SST gradient $\left({ }^{\circ} \mathrm{C} / 100 \mathrm{~km}\right)$

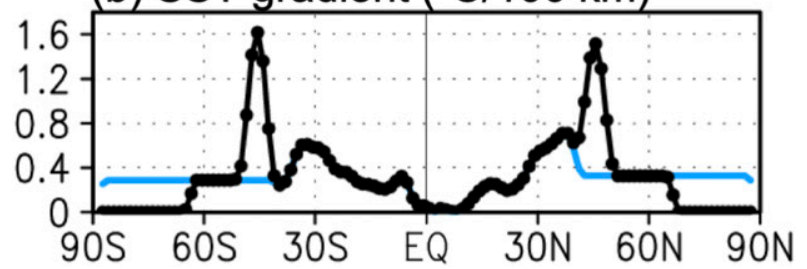

FIG. 1. Latitudinal profiles of (a) SST $\left({ }^{\circ} \mathrm{C}\right)$ prescribed as the lowerboundary conditions for AGCM experiments and (b) magnitudes of meridional SST gradients $\left[{ }^{\circ} \mathrm{C}(100 \mathrm{~km})^{-1}\right]$. The profiles for CTL and NF experiments are plotted with black and blue solid lines, respectively.

"aquaplanet" setting where no landmass and sea ice exist, the forcing of planetary waves as in the Northern Hemisphere is suppressed, allowing us to investigate the fundamental dynamics of the BAM.

The rest of this paper is structured as follows. Details of the aquaplanet experiments and analysis procedures are described in section 2. After an overview of the climatological-mean fields simulated in our experiments is presented in section 3 , characteristics of the BAM and the effect of the oceanic frontal zone are described in section 4. Detailed dynamics of the BAM and the influence from the ocean are discussed in section 5 by investigating the time evolution of the BAM. In section 6 , our findings of the relationship between the BAM and SAM are discussed. In section 7, we re-examine the quasi-periodic behavior of the BAM pointed out by TW14 and TB14. Concluding remarks are presented in section 8.

\section{Data and method}

In this study, we analyze the output of aquaplanet experiments conducted by Ogawa et al. $(2012,2016)$ with the AGCM for Earth Simulator (AFES; Ohfuchi et al. 2007; Enomoto et al. 2008; Kuwano-Yoshida et al. 2010). In the experiments, the model horizontal resolution of T79 corresponds to $\sim 150$-km grid intervals and is adequate to resolve a strong SST gradient associated with an oceanic frontal zone as observed in the south Indian Ocean. The model has 56 vertical levels up to $0.09 \mathrm{hPa}$.

As the model lower-boundary condition for the experiments, a hypothetical water-covered globe is assumed with no landmass and sea ice, as in Nakamura et al. (2008) and Sampe et al. (2010, 2013). The prescribed SST profiles (Fig. 1) are perpetual and zonally uniform. For assessing the effect of 
oceanic frontal zones, we compare the control (CTL) and "nonfront" (NF) experiments conducted by Ogawa et al. (2012, 2016). The meridional SST profile prescribed in the CTL experiment is based on the Optimal Interpolation Sea Surface Temperature (OISST) data produced by the National Oceanic and Atmospheric Administration (Reynolds et al. 2007). The climatological-mean meridional SST profiles over the south Indian Ocean $\left(60^{\circ}-80^{\circ} \mathrm{E}\right)$ for austral summer (DecemberFebruary) and austral winter (June-August) are prescribed to the model Northern and Southern Hemispheres, respectively, which are characterized by oceanic frontal zones at $45^{\circ}$ latitude. The maximum meridional SST gradient is $\sim 1.51^{\circ} \mathrm{C}$ $(100 \mathrm{~km})^{-1}\left[\sim 1.62^{\circ} \mathrm{C}(100 \mathrm{~km})^{-1}\right]$ for the model Northern (Southern) Hemisphere. The insolation is fixed to the summer (winter) solstice condition in the model Northern (Southern) Hemisphere. The model Northern (Southern) Hemisphere thus corresponds to austral summer (winter). For robust statistics, the model was integrated for 120 months after 6 months for spinup. The 120-month model output is thus equivalent to daily data over 40 summer/winter seasons.

In the NF experiment, by contrast, meridional SST gradients between the equatorward flank of the oceanic frontal zone $\left(\sim 41^{\circ}\right)$ and the pole are replaced with reduced uniform SST gradients of $0.33^{\circ} \mathrm{C}(100 \mathrm{~km})^{-1}$ and $0.29^{\circ} \mathrm{C}(100 \mathrm{~km})^{-1}$ for the model Northern and Southern Hemispheres, respectively, in order to eliminate the midlatitude oceanic frontal zones. In the NF experiment, SST poleward of $\sim 45^{\circ}$ is therefore substantially higher than that in the CTL experiment, which acts to enhance surface evaporation and thus precipitation associated with cyclones. Despite this condition favorable for cyclone development, the storm track activity is reduced substantially in the NF experiment, as shown later, which highlights the importance of the frontal SST gradient for storm track activity. Meanwhile, SST equatorward of the oceanic frontal zone is kept the same between the CTL and NF experiments to suppress any tropically forced modifications in the Hadley cell and subtropical jet (STJ) that can complicate our interpretation of the impacts of the midlatitude frontal SST gradients on the STJ.

In the CTL experiment, meridional SST gradients poleward of the frontal zones have been replaced with the same uniform SST gradients as in the NF experiment. In both experiments, the minimum SST is set to $-1.79^{\circ} \mathrm{C}$ to realize ice-free conditions and thereby eliminate strong thermal contrast across sea ice boundaries. In this manner, the model setting is suited for extracting the effect of the midlatitude oceanic frontal zones. Still, the difference in the meridional SST profiles between the two experiments is so large that the results shown below should be regarded as an upper bound of the potential impacts of the oceanic frontal zone on the observed BAM.

In this study, subweekly fluctuations of a given variable associated with transient disturbances (denoted below with primes) are extracted with a high-pass filter with a cutoff period of 8 days, as in Ogawa et al. (2012, 2016). Although zonal averages of individual variables have not been removed in defining the subweekly fluctuations, we have confirmed that zonally symmetric signals are negligible in the high-passfiltered fields. Kinetic energy (KE) associated with transient disturbances (TKE) is evaluated locally as $\left(u^{\prime 2}+v^{\prime 2}\right) / 2$, where $u$ and $v$ denote zonal and meridional wind velocities, respectively. Meridional heat and westerly momentum fluxes as well as an upward heat flux all associated with transient disturbances are defined as $v^{\prime} T^{\prime}, u^{\prime} v^{\prime}$, and $-\omega^{\prime} T^{\prime}$, respectively, where $\omega$ denotes pressure velocity and $T$ air temperature. For conciseness, we define positive $v$ as a poleward meridional motion so that positive values of $v^{\prime} T^{\prime}$ and $u^{\prime} v^{\prime}$ in each hemisphere correspond to poleward fluxes of heat and westerly momentum, respectively. Low-frequency variability of a given variable and the low-frequency modulations in the statistics such as TKE and the various fluxes are extracted through 8-day low-pass filtering. Climatological means and anomalies are defined as 120-month averages and deviations from them, respectively.

In this study, the BAM is defined as the first EOF (EOF1) of low-frequency variability in [TKE], where the square brackets represent a zonal-mean statistic. Unlike in the previous studies (e.g., TW14), we use TKE rather than $\mathrm{EKE}^{1}$ in defining the BAM to highlight the contributions of typical synoptic-scale transient disturbances that are active along storm tracks. An EOF analysis was applied separately to each of the model hemispheres within the meridional domain defined by $20^{\circ}-70^{\circ}$ in latitude and from the $925-$ to $200-\mathrm{hPa}$ levels. This domain is almost the same as used in TW14. Prior to the EOF analysis, the data have been weighted with both the square root of the cosine of latitude and the mass represented by each pressure level. The normalized principal component time series for EOF1 is hereinafter referred to as a "BAM index." By definition, its positive values correspond to positive anomalies of [TKE].

As the reference dataset, we analyze the corresponding daily statistics derived from the Japanese 55-Year Reanalysis (JRA55; Kobayashi et al. 2015), which is available on a $1.25^{\circ} \times 1.25^{\circ}$ grid system. The results shown below are based on the data from 1979 to 2017, and this 39-yr period is comparable to the data length of our aquaplanet experiments. Climatological means of the individual variables and statistics have been calculated by first applying 31-day running mean and then 39-yr averaging for each calendar day. Anomalies of a given variable are defined as deviations from its climatological mean.

The BAM signature in JRA-55 has been extracted as EOF1 of 8-day low-pass-filtered daily anomalies of [TKE] within the aforementioned meridional domain. The EOF analysis was applied separately for austral winter (June-August) and summer (December-February) to investigate the seasonality of the BAM and make a straightforward comparison with our perpetual aquaplanet experiments. The data have been weighted in the same manner as the analysis for the aquaplanet experiments.

\section{Model reproducibility of the climatological-mean state}

Before discussing the characteristics of the model-simulated BAM, we present an overview in Figs. 2 and 3 of the

\footnotetext{
${ }^{1}$ In previous works (e.g., TW14), EKE is defined as $\left(u^{*^{2}}+v^{*^{2}}\right) / 2$, where an asterisk $(*)$ denotes a departure from the zonal mean. The difference in the BAM based on TKE and EKE is discussed in section 7 .
} 


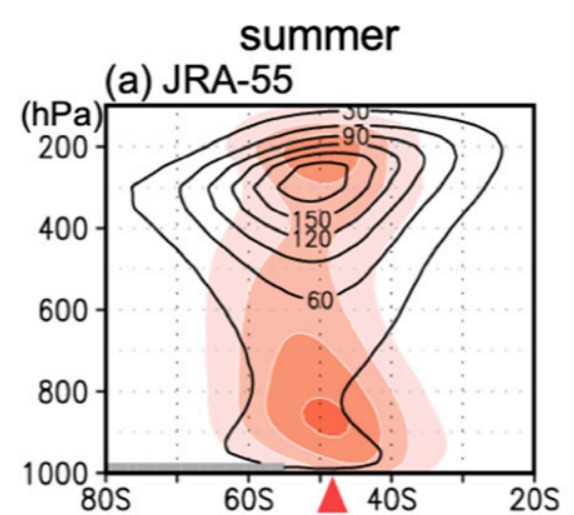

(c) CTL

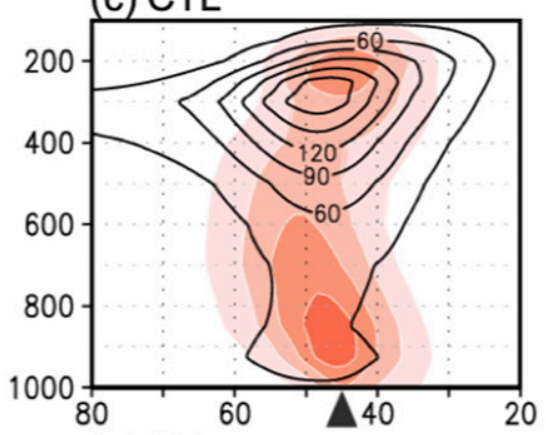

(e) NF

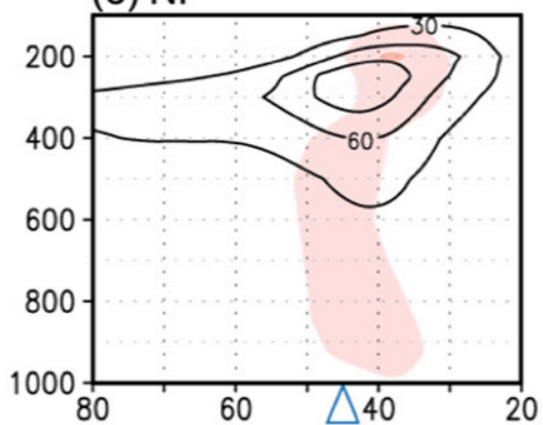

(b) JRA-55

winter

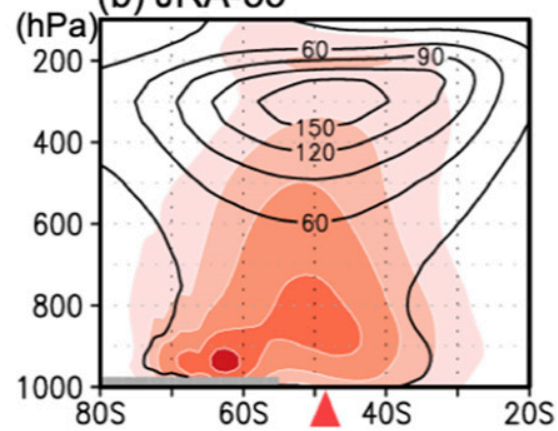

(d) CTL

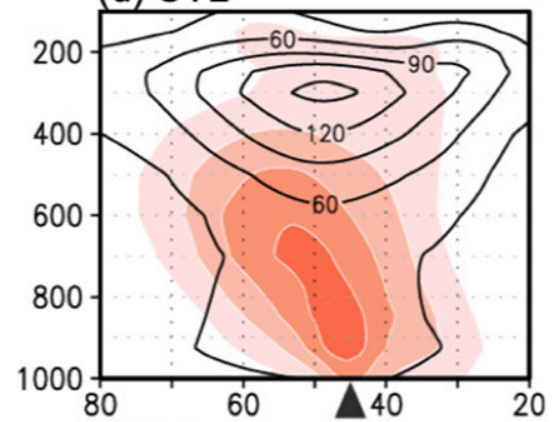

(f) NF

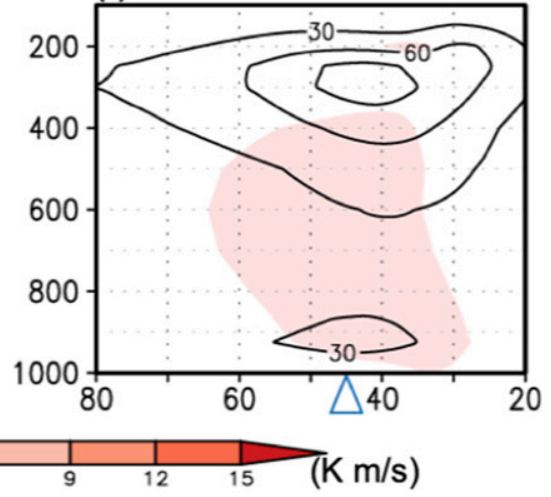

FIG. 2. Meridional sections of the climatological-mean [TKE] (contour; $\mathrm{m}^{2} \mathrm{~s}^{-2}$ ) and poleward $\left[v^{\prime} T^{\prime}\right]$ (shading; $\mathrm{K} \mathrm{m} \mathrm{s}^{-1}$ ) based on JRA-55 for the SH (a) summer and (b) winter. (c),(d) As in (a) and (b), respectively, but for the model summer and winter hemispheres of the CTL experiment. (e),(f) As in (c) and (d), respectively, but for the NF experiment. Red triangles indicate zonally averaged latitudes of the oceanic frontal zone observed in the $\mathrm{SH}\left(\sim 48.5^{\circ} \mathrm{S}\right)$, as calculated by zonally averaging the latitudes of the maximum SST gradient, weighted by the magnitude of the corresponding SST gradient. Black triangles indicate the corresponding latitude in the SST profile for the CTL experiment $\left(45.6^{\circ}\right)$, which are also indicated with blue cusps for the NF experiment as a reference.

climatological-mean storm track activity and $[u]$, respectively, simulated in the aquaplanet AFES experiments and observed in the SH. In both the winter and summer hemispheres of the CTL experiment (Figs. 2c,d and 3c,d), both the storm track axis marked by meridional maxima in [TKE] and $\left[v^{\prime} T^{\prime}\right]$ and eddy-driven PFJ axis, into which upper-level momentum flux associated with transient disturbances converges, are collocated near the oceanic frontal zone at $45^{\circ}$ (indicated with black triangles). The collocation is in agreement with the observations (Figs. 2a,b and 3a,b) and previous studies (Nakamura et al. 2008; Sampe et al. 2010; Ogawa et al. 2012). The removal of the oceanic frontal zones leads to marked reductions in both the storm track activity and PFJ strength in addition to equatorward shifts of their axes by $\sim 5^{\circ}$ (Figs. $2 \mathrm{e}, \mathrm{f}$ and $3 \mathrm{e}, \mathrm{f})$. These results suggest that the oceanic frontal zones energize subweekly transient disturbances, thereby anchoring 

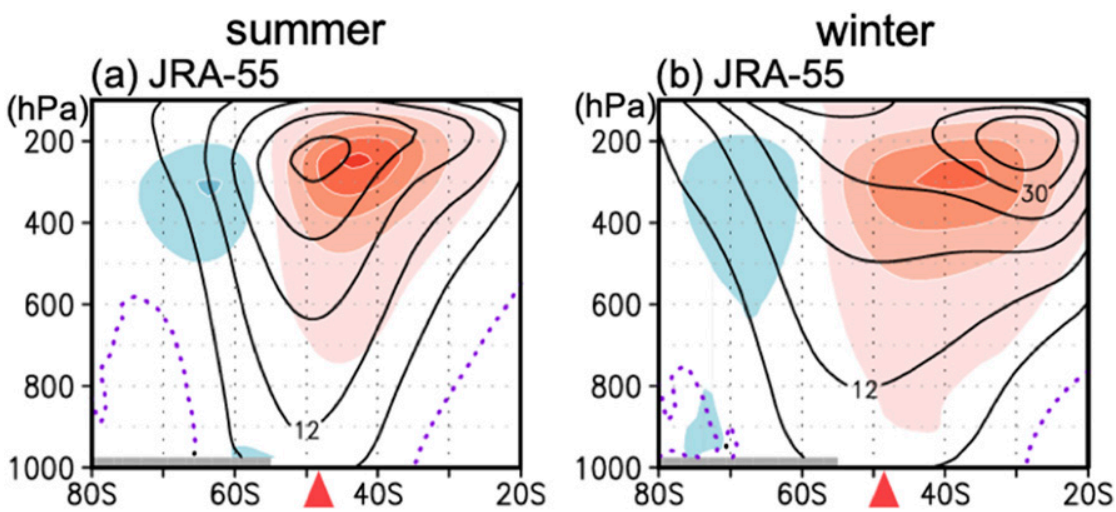

(c) CTL
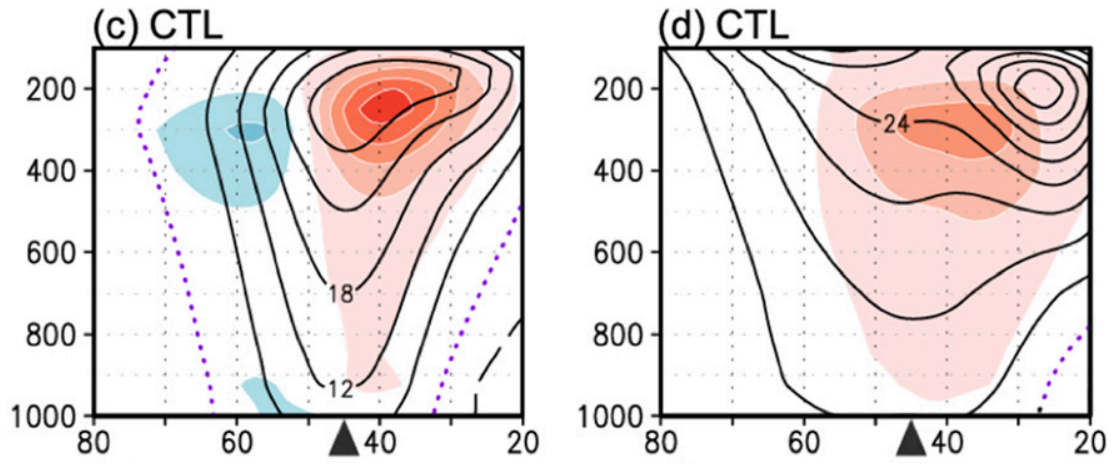

(e) NF

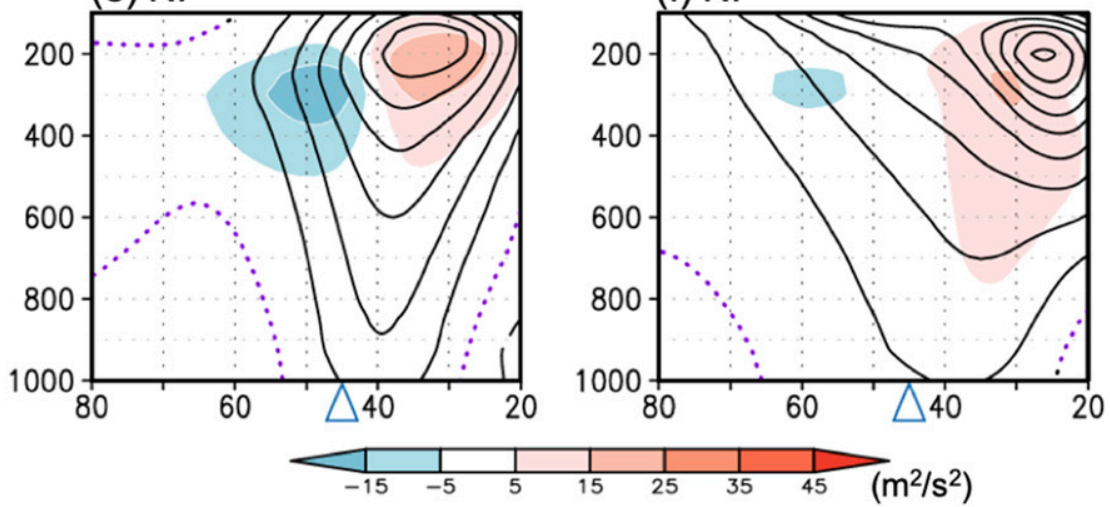

FIG. 3. As in Fig. 2, but for the climatological-mean $[u]$ (contour; $\mathrm{m} \mathrm{s}^{-1}$; dashed lines for the easterlies) and poleward $\left[u^{\prime} v^{\prime}\right]$ (shading; $\mathrm{m}^{2} \mathrm{~s}^{-2}$ ). Purple dotted lines represent zero lines of $[u]$.

the storm track and PFJ climatologically (Nakamura et al. 2004, 2008).

Figures 2 and 3 also reveal the seasonality of the storm track and PFJ. In the lower and midtroposphere, the storm track activity measured by $\left[v^{\prime} T^{\prime}\right]$ is somewhat weaker in the austral summer than in the winter, whereas the opposite is the case in the upper troposphere in both the experiments and reanalysis. The weakening of storm track activity around the midlatitude PFJ core in austral winter is also evident in [TKE], especially in the CTL experiment and reanalysis. The weakening is probably because part of the storm track activity tends to be trapped into the intense STJ core in austral winter (Nakamura and Shimpo 2004). The upper-level storm track marked as large [TKE] is meridionally broader in austral winter, especially in the
CTL experiment and reanalysis data. In austral winter (Fig. 2b), another local maximum of $\left[v^{\prime} T^{\prime}\right]$ is observed near the surface at $\sim 60^{\circ} \mathrm{S}$, where strong thermal contrast across the sea ice boundary is located. Without sea ice, the corresponding maximum of $\left[v^{\prime} T^{\prime}\right]$ is absent in the aquaplanet experiments (Figs. 2d,f).

Though idealized, the CTL experiment thus well reproduces the seasonality in the storm track activity and the westerlies observed in the SH as shown by Nakamura and Shimpo (2004) (Figs. 2a,b and 3a,b), including the close association among the storm track, eddy-driven PFJ, and the oceanic frontal zone (Nakamura et al. 2004). There is a slight difference, however, in the latitudinal positions of their axes, which is $\sim 45^{\circ}$ in the CTL experiment but $\sim 50^{\circ}$ in the observations. This is consistent with the slight latitudinal difference of the oceanic frontal 
zone between the CTL experiment and observations (indicated with black and red triangles, respectively). These results confirm the importance of the midlatitude oceanic frontal zone in the formation of the storm track and associated PFJ, as postulated by Nakamura et al. (2004, 2008), Sampe et al. (2010), and Ogawa et al. (2012).

\section{Model BAM and its sensitivity to the oceanic frontal zone}

In each of the model hemispheres, EOF1 of [TKE], which represents the BAM, explains more than half of the total variance, as in the observations (Table 1). In each of the experiments, EOF1 accounts for a slightly smaller fraction of the [TKE] variance in austral winter than in summer, as observed. Nevertheless, EOF1 is still dominant and well separated from the second EOF (EOF2) in both seasons, according to the criterion by North et al. (1982). Interestingly, EOF1 in the NF experiment is even better separated from EOF2 than in the CTL experiment.

Figure 4 shows anomalies of [TKE] and poleward $\left[v^{\prime} T^{\prime}\right]$ both regressed against the $\mathrm{BAM}$ indices, which are thus typical for its positive phase. In the CTL experiment, broad meridional monopole structures are evident in both the [TKE] and $\left[v^{\prime} T^{\prime}\right]$ anomalies in each of the hemispheres (Figs. 4c,d), which is overall consistent with the observed BAM (Figs. 4a,b) in our analysis and TW14. These anomalies peak at the latitude of the oceanic frontal zone or slightly poleward in both the CTL experiment and reanalysis, corresponding to the peak latitude of the climatological-mean storm track activity (Figs. 2a-d). Therefore, the BAM represents such pulsing of the storm track activity that a unit standard deviation of the BAM index corresponds to $\sim 25 \%$ changes in [TKE] and $\left[v^{\prime} T^{\prime}\right]$ from their climatological means in the upper and lower troposphere, respectively.

Figure 5 shows anomalies of $[u]$ and poleward $\left[u^{\prime} v^{\prime}\right]$ regressed against the BAM indices in the same manner as in Fig. 4. In the CTL experiment, the regressed anomalies in $[u]$ exhibit positive and negative peaks poleward and equatorward, respectively, of the climatological PFJ core (Figs. 5c,d), as in the reanalysis (Figs. 5a,b). Therefore, the BAM represents a slight meridional shift of the PFJ axis rather than pulsing of its intensity. This feature is consistent with the anomalous forcing on the PFJ via anomalous upper-level poleward $\left[u^{\prime} v^{\prime}\right]$, which is divergent around the anomalous easterlies and convergent around the anomalous westerlies both in the reanalysis and CTL experiment (Figs. 5a-d). If composited separately for positive and negative events of the BAM, slight but significant latitudinal differences of the PFJ axis (by $1^{\circ}-2^{\circ}$ ) are detected, especially in the summer hemisphere for each of the two experiments and reanalysis (Table 2). Although not pointed out by TW14, these BAM signatures observed in the PFJ will be discussed further in section 6.

Figures 4 and 5 also reveal the seasonality of the BAM anomalies, which was not discussed by TW14. Uppertropospheric anomalies in storm track activity are weaker in austral winter than in summer, while wintertime [TKE] anomalies are meridionally broader, as pointed out by Wang
TABLE 1. Fraction (\%) of the total variance of [TKE] explained by EOF1 (EOF2).

\begin{tabular}{lcc}
\hline \hline & Summer & Winter \\
\hline JRA-55 & $65.9(18.2)$ & $52.9(23.1)$ \\
CTL & $62.7(20.3)$ & $56.2(18.9)$ \\
NF & $70.0(10.7)$ & $60.1(16.5)$ \\
\hline
\end{tabular}

and Nakamura (2016). In the lower and midtroposphere, by contrast, anomalies in storm track activity, especially $\left[v^{\prime} T^{\prime}\right]$, are stronger in the winter hemisphere. As pointed earlier, another peak of anomalous $\left[v^{\prime} T^{\prime}\right]$ is observed near the surface in austral winter at $60^{\circ}-65^{\circ} \mathrm{S}$, corresponding to its climatological maximum. These BAM-associated anomalies in storm track activity and their seasonality both exhibit strong correspondence to their climatological-mean counterpart (Fig. 2), representing the pulsing of the storm track activity as the characteristic of the BAM (TW14). The seasonality in the structure and amplitude of the BAM anomalies thus reflects those in the climatological-mean storm track activity in both the CTL experiment and reanalysis.

In the NF experiment, the regressed anomalies of storm track activity and $[u]$ are markedly weakened while shifted equatorward by $5^{\circ}-10^{\circ}$ (Figs. $4 \mathrm{e}, \mathrm{f}$ and $5 \mathrm{e}, \mathrm{f}$ ) relative to their counterpart in the CTL experiment. Figures $6 \mathrm{a}-\mathrm{d}$ compare latitudinal profiles of the BAM-associated anomalies in low-level $\left[v^{\prime} T^{\prime}\right]$ and upper-level [TKE] between the two experiments. The weakening in the anomalous storm track activity is $30 \%-40 \%$ in the upper troposphere (Figs. 6c,d), whereas that in lower-tropospheric $\left[v^{\prime} T^{\prime}\right]$ reaches as much as $65 \%$ (Figs. 6a,b). The BAM-associated $\left[v^{\prime} v^{\prime}\right]$ and $\left[T^{\prime} T^{\prime}\right]$ anomalies are larger in the CTL experiment than in the NF experiment, with statistical significance at the $99 \%$ confidence level (not shown). The marked weakening of the BAM anomalies by eliminating the frontal SST gradient is very similar to the corresponding weakening in their climatological means (Fig. 2). The magnitude ratio of the BAM anomalies to the corresponding climatological means is comparable between the CTL and NF experiments. Therefore, these results suggest that the BAM is essentially a manifestation of atmospheric internal dynamics, but the oceanic frontal zone significantly amplifies the BAM variability.

\section{Time evolution of the BAM anomalies}

The dynamics of the BAM anomalies can be understood deeper by investigating their typical time evolution, as shown in lag-latitude sections in Figs. 7-10, where the anomalies are regressed against the BAM indices based on the aquaplanet experiments and the reanalysis. In the summer hemisphere of the CTL experiment (middle column in Fig. 7), [TKE] anomalies maximize, by definition, simultaneously with the BAM index, while the peak times of $\left[v^{\prime} T^{\prime}\right]$ and $\left[-\omega^{\prime} T^{\prime}\right]$ anomalies precede the [TKE] peak by $\sim 1$ day. As pointed out by TW14, this lag relationship is consistent with the energetics of baroclinic development of synoptic-scale disturbances, where available potential energy (APE) associated with the 
(a) JRA-55

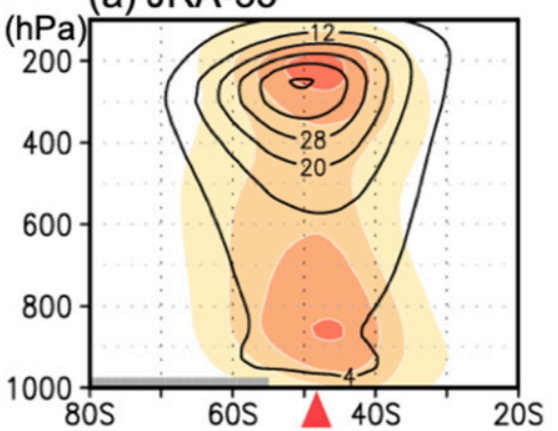

(c) CTL

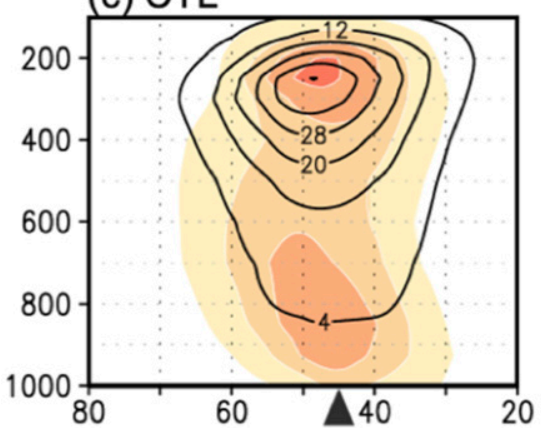

(e) NF

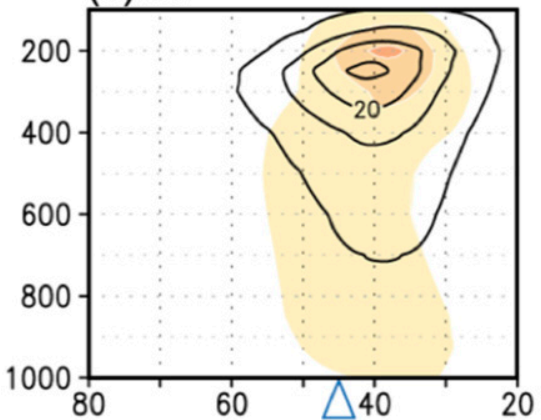

(b) JRA-55

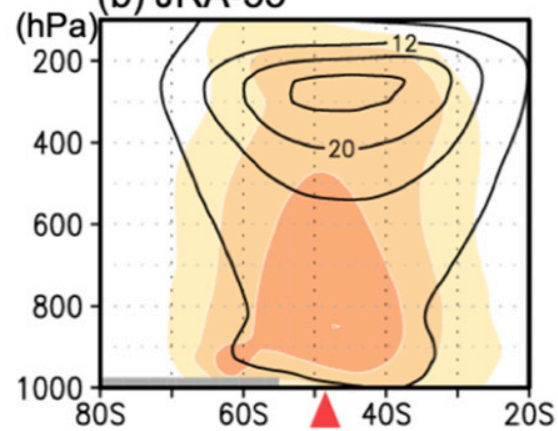

(d) CTL

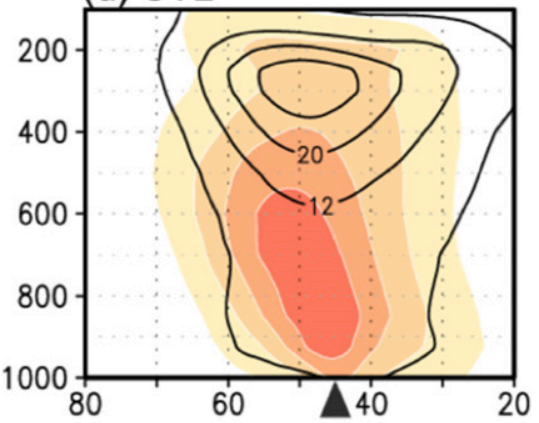

(f) NF

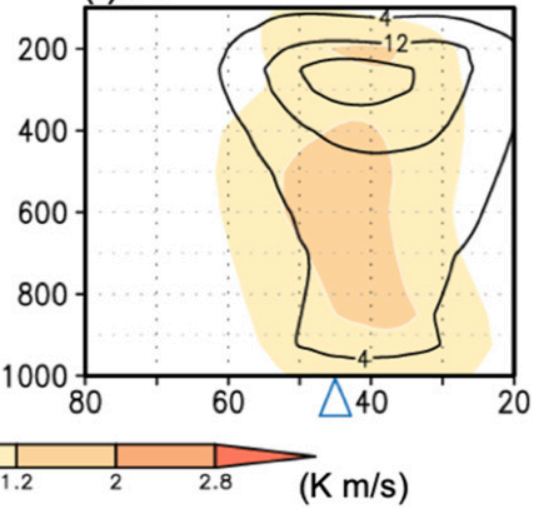

FIG. 4. As in Fig. 2, but for anomalies in [TKE] (contour, $\mathrm{m}^{2} \mathrm{~s}^{-2}$ ) and poleward $\left[v^{\prime} T^{\prime}\right]$ (shading; $\mathrm{K} \mathrm{m} \mathrm{s}^{-1}$ ) regressed against the BAM index based on JRA-55 for the SH (a) summer and (b) winter. The $\left[v^{\prime} T^{\prime}\right]$ anomalies precede the corresponding BAM index by 1 day. (c),(d) As in (a) and (b), respectively, but for the model summer and winter hemispheres in the CTL experiment. (e),(f) As in (c) and (d), respectively, but for the NF experiment.

zonal-mean state [ZAPE] is converted to APE associated with transient disturbances [TAPE] and then to [TKE]. The peak times of the $\left[u^{\prime} v^{\prime}\right]$ and $[u]$ anomalies lag the [TKE] peak by $\sim 1$ day and 1-3 days, respectively, which is also consistent with the energy conversion from [TKE] to zonal-mean KE. The entire evolution of the BAM signature thus corresponds to a typical life cycle of baroclinic disturbances. The aforementioned lead-lag relationship overall holds also in the reanalysis (left column in Fig. 7), confirming the reproducibility of the BAM dynamics in the CTL experiment. Virtually the same lead-lag relationship of the peaks of $\left[v^{\prime} T^{\prime}\right]$ and $\left[-\omega^{\prime} T^{\prime}\right]$ anomalies relative to that of [TKE] anomalies is found in the NF experiment (right column in Fig. 7), although the corresponding anomalies are substantially weaker and displaced equatorward. Therefore, these experiments suggest that the essential dynamics of the BAM is atmospheric internal dynamics, where frontal SST gradients energize subweekly baroclinic disturbances so as to augment the BAM variability. In fact, magnitudes of the anomalies in storm track activity and $[u]$ are reduced by $25 \%-60 \%$ in the NF experiment relative to the CTL experiment (Figs. 4, 5, and 6). 


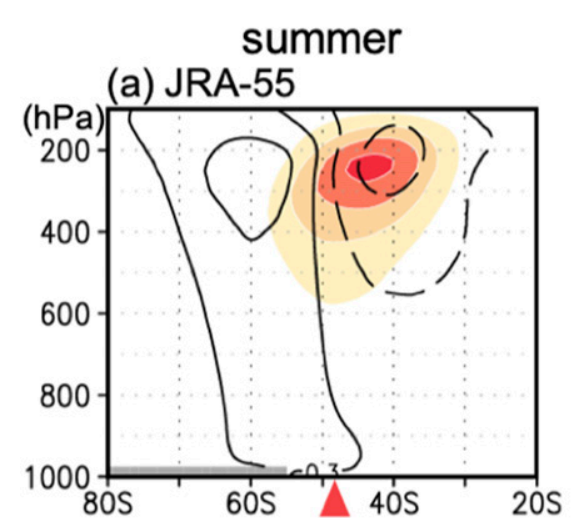

(c) CTL

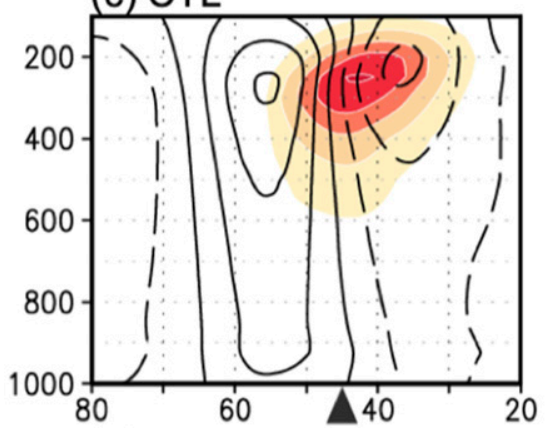

(e) NF

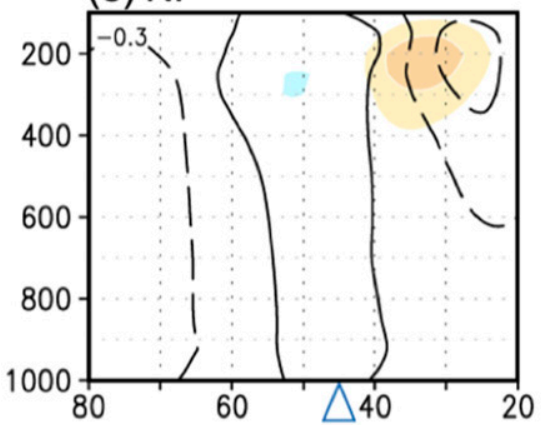

(b) JRA-55

winter

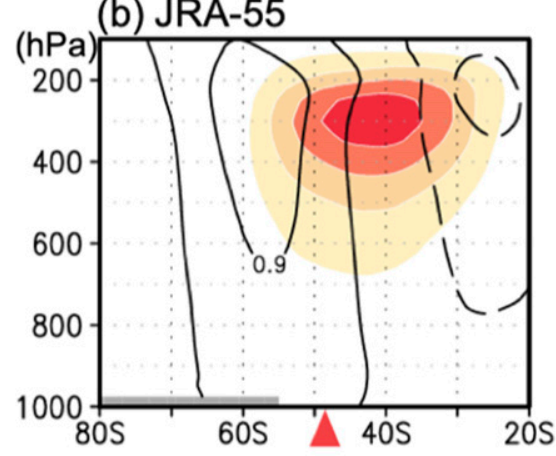

(d) CTL

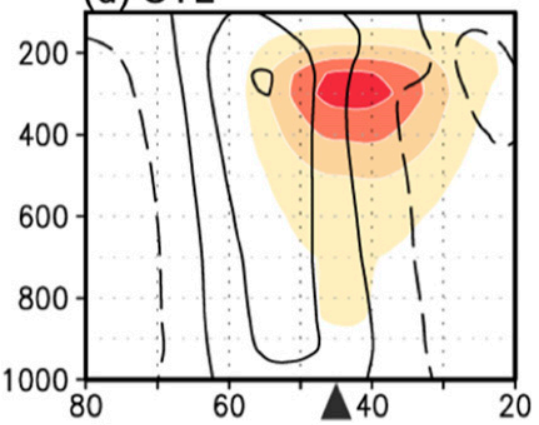

(f) NF

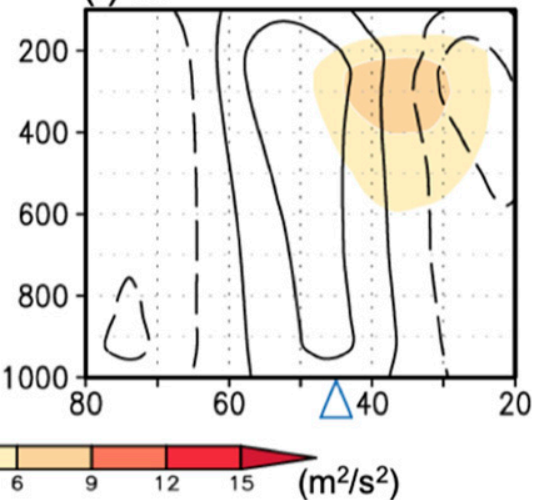

FIG. 5. As in Fig. 4, but for the anomalies in $[u]\left(\right.$ contour; $\mathrm{m} \mathrm{s}^{-1}$ ) and poleward $\left[u^{\prime} v^{\prime}\right]$ (shading; $\mathrm{m}^{2} \mathrm{~s}^{-2}$ ) regressed onto the BAM index. The $[u]$ anomalies lag behind the corresponding index by 2 days.

The influence of the oceanic frontal zones on the BAM anomalies can be highlighted in the associated heat and moisture exchanges with the underlying ocean, as revealed in their lag-regression anomalies (Fig. 8). In each of the experiments and reanalysis, the positive phase of the BAM accompanies significant anomalies in zonal-mean surface air temperature [SAT] that are negative in the subtropics and positive in midlatitudes (Figs. 8a-c). The meridional structure of [SAT] anomaly reflects the enhanced poleward heat transport by transient disturbances associated with the positive BAM, as evident in the delayed peak of the midlatitude [SAT] anomalies relative to the [TKE] peak. Figures $8 \mathrm{~d}-\mathrm{f}$ show the BAM-associated zonal-mean anomalies in surface sensible heat flux [SHF], which is defined to be positive when upward from the ocean. The anomalous $[\mathrm{SHF}]$ exhibits almost the same latitudinal distribution as the anomalous [SAT] but with the opposite signs (Figs. 8a-c). Figures $6 \mathrm{e}$ and $6 \mathrm{~g}$ show the corresponding BAM-associated anomalies in meridional gradients of [SAT] and [SHF], respectively, for the aquaplanet experiments. In the positive phase of the BAM, the meridional [SAT] gradient across the storm track is reduced (Fig. 6e), but the reduction accounts only for $1 \%$ of its climatological-mean value in each of the experiments per unit standard deviation of the BAM index. Likewise, the corresponding fractional reduction in the $925-\mathrm{hPa}$ zonal-mean temperature gradient is also only $5 \%(3 \%)$ in the CTL (NF) experiment (not shown). 
TABLE 2. Latitudes $\left({ }^{\circ}\right)$ of PFJ axis, defined as the 850-hPa $[u]$ maximum, averaged separately for the positive and negative phases of the BAM. The former and latter are defined as the days when the BAM index exceeds a unit standard deviation positively and negatively, respectively. Latitudinal differences between the two phases ("positive" minus "negative") are shown in the bottom row. Asterisks (*) denote the difference significant at the $95 \%$ confidence level. The zonal-mean latitude of the midlatitude oceanic frontal zone is indicated in parentheses.

\begin{tabular}{|c|c|c|c|c|c|c|}
\hline & \multicolumn{3}{|c|}{ Summer } & \multicolumn{3}{|c|}{ Winter } \\
\hline & JRA-55 $\left(48.3^{\circ}\right)$ & $\operatorname{CTL}\left(45.6^{\circ}\right)$ & $\overline{\mathrm{NF}}$ & JRA-55 $\left(48.5^{\circ}\right)$ & $\operatorname{CTL}\left(45.6^{\circ}\right)$ & $\overline{\mathrm{NF}}$ \\
\hline BAM positive & 50.40 & 47.47 & 41.93 & 51.38 & 48.47 & 43.81 \\
\hline BAM negative & 49.93 & 45.91 & 41.57 & 50.93 & 46.88 & 42.62 \\
\hline Difference & $* 0.47$ & $* 1.56$ & $* 0.36$ & 0.45 & $* 1.59$ & $* 1.19$ \\
\hline
\end{tabular}

By contrast, the meridional $[\mathrm{SHF}]$ gradient across the oceanic frontal zone increases by $9 \%$ from its climatology (Fig. $6 \mathrm{~g}$ ). Thus, the [SHF] anomalies act to restore the meridional [SAT] gradient modified by the BAM activity, as operative climatologically along oceanic frontal zones (Nonaka et al. 2009; Sampe et al. 2010; Hotta and Nakamura 2011). Under the assumption of the 1-km depth for the atmospheric mixed layer, the above restoration is very efficient with a typical time scale of less than a day. In the $\mathrm{SH}$, despite landmasses and zonal asymmetries of the SST front, the above restoration is still evident with comparable efficiency around $45^{\circ} \mathrm{S}$, where the major oceanic frontal zone exists climatologically as marked with red triangles in Figs. 8a and 8d.

A comparison between the CTL and NF experiments highlights the influence of the oceanic frontal zone. In the CTL experiment, the meridional [SHF] gradient is enhanced across the oceanic frontal zone at $45^{\circ}$ (Fig. $6 \mathrm{~g}$ ) under the enhanced $\left[v^{\prime} T^{\prime}\right]$ (Fig. 6a), which allows the efficient restoration of the meridional [SAT] gradient to maintain the anomalous storm track activity. In fact, a similar association is found in the observed BAM (Figs. 7a and 8d). In the NF experiment, however, the meridional gradient of the anomalous [SHF] weakens by $\sim 65 \%$ relative to the CTL experiment (Fig. $6 \mathrm{~g}$ ). Reflecting the weakness of the background [SAT] gradient, the restoration time scale for the meridional [SAT] gradient is also shorter than a day but still $\sim 10 \%$ longer than in the CTL experiment. The significantly larger anomalous meridional [SHF] gradient in the CTL experiment (Fig. 6g) suggests that the enhanced anomalous $[\mathrm{SHF}]$ in the presence of the oceanic frontal zone allows the effective restoration of near-surface baroclinicity for recurrent development of baroclinic disturbances and thereby maintains enhanced storm track activity during the positive phase of the BAM.

The BAM also accompanies zonal-mean moisture anomalies. In both the CTL experiment and reanalysis in the summer hemisphere, the zonal-mean precipitation anomaly peaks almost simultaneously with the [TKE] anomaly around $55^{\circ}$ (Figs. 8j,k) on the poleward side of the storm track. The anomaly might represent enhanced condensation associated with enhanced poleward-moving warm moist airflows under the augmented storm track activity. Energetically, the enhanced latent heat release within the warm poleward airflow can lead to increased [TAPE] generation. The enhanced precipitation also corresponds to the peak of anomalous $\left[-\omega^{\prime} T^{\prime}\right]$ for the increased conversion to [TKE] (Fig. 7e). The [TAPE] generation with anomalous precipitation is evident also in the reanalysis, where the peak time of anomalous precipitation at $45^{\circ}-50^{\circ} \mathrm{S}$ around the storm track axis precedes the [TKE] peak by 1-2 days (Fig. $8 \mathrm{j}$ ). The precipitation anomaly can be supported in part by anomalous evaporation [i.e., upward latent heat flux (LHF)] from the warm ocean (Fig. 8h) under the subtropical high pressure belt $\left(\sim 30^{\circ}\right.$ latitude, marked with a zero line of climatological near-surface $[u]$ in Fig. 3). Actually, enhanced poleward moisture flux associated with transient disturbances is observed in the lower troposphere (not shown).

In the summer hemisphere of the NF experiment, the subpolar center of zonal-mean precipitation anomalies shifts equatorward by $\sim 5^{\circ}$, while another peak is evident at $\sim 40^{\circ}$ latitude. This equatorward shift is consistent with the corresponding shift of storm track activity (Figs. 3c-f). The precipitation anomaly is $\sim 20 \%$ larger than in the CTL experiment despite the weaker anomalous storm track activity (Figs. 8k,1), because probably of the higher SST poleward of $45^{\circ}$ in the NF experiment (Fig. 1a). The slightly stronger precipitation anomaly in the NF experiment could lead to enhanced generation of [TKE]. In reality, however, the [TKE] anomaly is reduced substantially in the NF experiment (Figs. 2e,f and 7i), which confirms the importance of the restoration of baroclinicity through anomalous [SHF] across the oceanic frontal zone in energizing the BAM activity.

The time evolution of the BAM anomalies in the winter hemisphere is shown in Figs. 9 and 10 in the same manner as in Figs. 7 and 8, respectively. As in the summer hemisphere, the essential dynamics of the wintertime BAM in the CTL experiment corresponds to a typical life cycle of baroclinic disturbances (Fig. 9), which is overall consistent with its counterpart in the reanalysis. In the NF experiment, anomalies in storm track activity and $[u]$ are overall weakened by removing the oceanic frontal zone, which again highlights the above-mentioned impacts of the frontal SST gradient on the BAM. Compared with the summer hemisphere, however, this weakening is less marked in the upper-tropospheric anomalies in [TKE] and $\left[u^{\prime} v^{\prime}\right]$, perhaps because the enhanced wintertime STJ acts as an effective waveguide (Nakamura and Shimpo 2004). Still, the weakening is pronounced in the lowertropospheric $\left[v^{\prime} T^{\prime}\right]$ anomalies in the absence of the SST front (Figs. 9b,c). The wintertime anomalies in [SHF] and [LHF] associated with the BAM are qualitatively the same as those in the summer hemisphere (Figs. 10d-i). The peak of the wintertime LHF anomaly shifts into the subtropics $\left(20^{\circ}-30^{\circ}\right.$ 


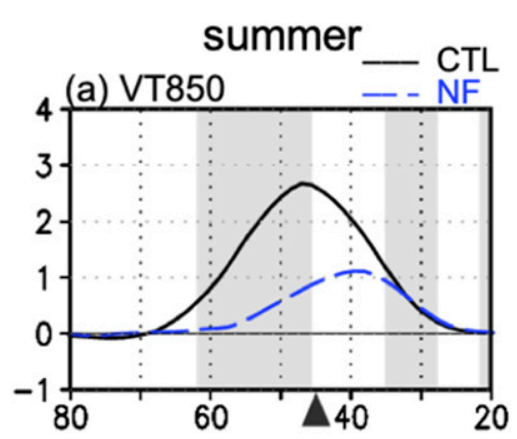

(c) TKE300
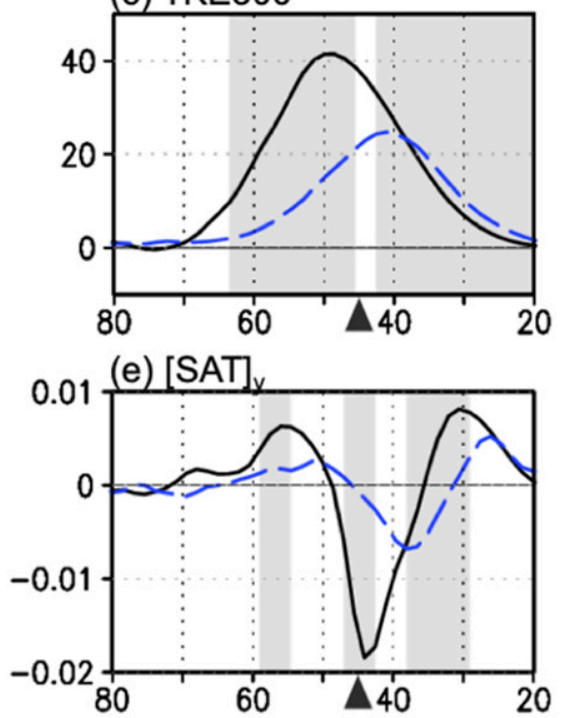

(g) $\left[\mathrm{SHF}_{\mathrm{y}}\right.$

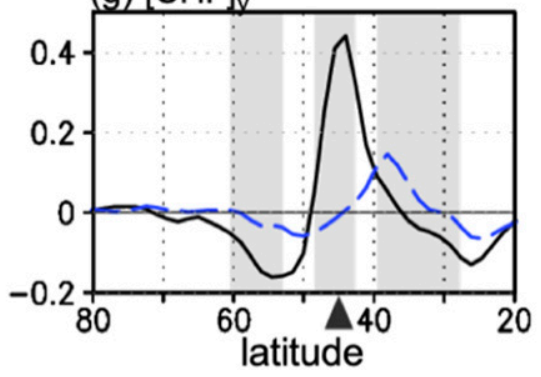

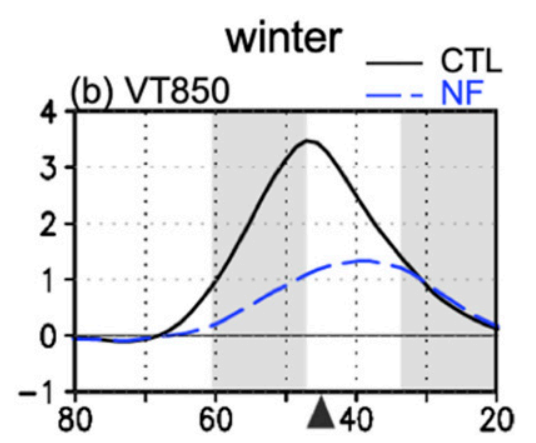

(d) TKE300
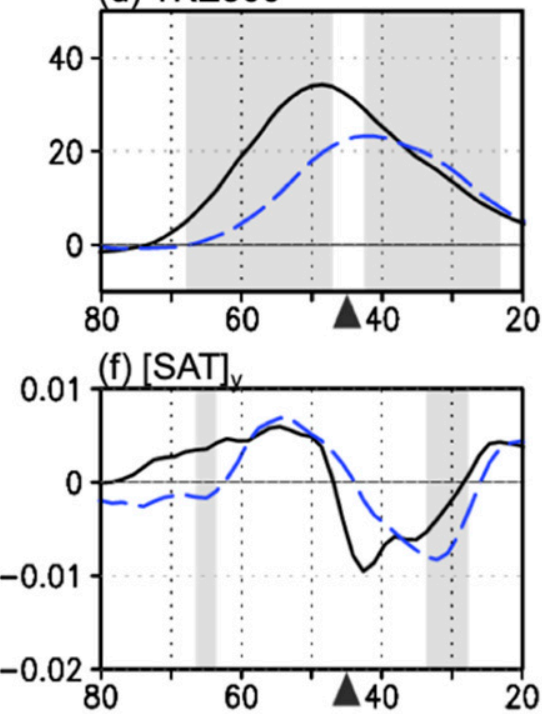

(h) $[\mathrm{SHF}]_{y}$

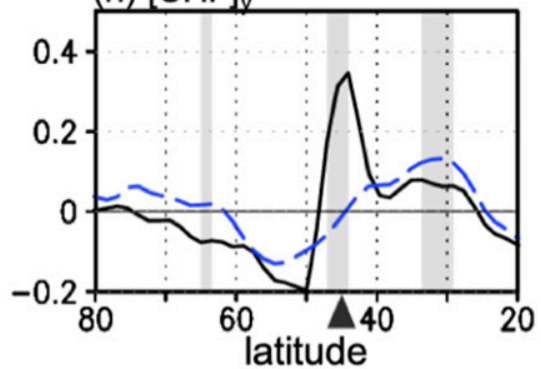

FIG. 6. Latitudinal profiles of anomalous (a),(b) 850-hPa poleward $\left[v^{\prime} T^{\prime}\right]\left(\mathrm{K} \mathrm{m} \mathrm{s}^{-1}\right)$, (c),(d) 300-hPa [TKE] $\left(\mathrm{m}^{2} \mathrm{~s}^{-2}\right),(\mathrm{e}),(\mathrm{f})$ meridional gradient of $2-\mathrm{m}$ temperature $[\mathrm{SAT}]\left[{ }^{\circ} \mathrm{C}(100 \mathrm{~km})^{-1}\right]$, and $(\mathrm{g}),(\mathrm{h})$ meridional gradient of upward sensible heat flux [SHF] [W m $\left.{ }^{-2}(100 \mathrm{~km})^{-1}\right]$, all linearly regressed against BAM index, separately for the CTL (black solid lines) and NF (blue dashed lines) experiments. Results shown for the model (left) summer and (right) winter hemisphere. Gray shading indicates significant difference between the two experiments at the $95 \%$ confidence level based on the corresponding correlation with the BAM index. In (e) and (h), positive gradients indicate decreases with latitudes. In (a) and (b), the $\left[v^{\prime} T\right]$ anomaly precedes the BAM index by 1 day. Black triangles indicate latitudes of the oceanic frontal zones in the CTL experiment.

latitude) in both experiments and the reanalysis, which is consistent with the meridional broadening of the BAM anomalies. It is also consistent with equatorward shifts of the Hadley cell and subtropical high pressure belt (identified as lines of climatological near-surface $[u]=0$ in Fig. 3).

\section{Relationship between the BAM and SAM}

As shown in Figs. 7m-r, the peak of the summertime BAMassociated [TKE] anomalies in each of the two experiments and the reanalysis tends to slightly precede the corresponding 

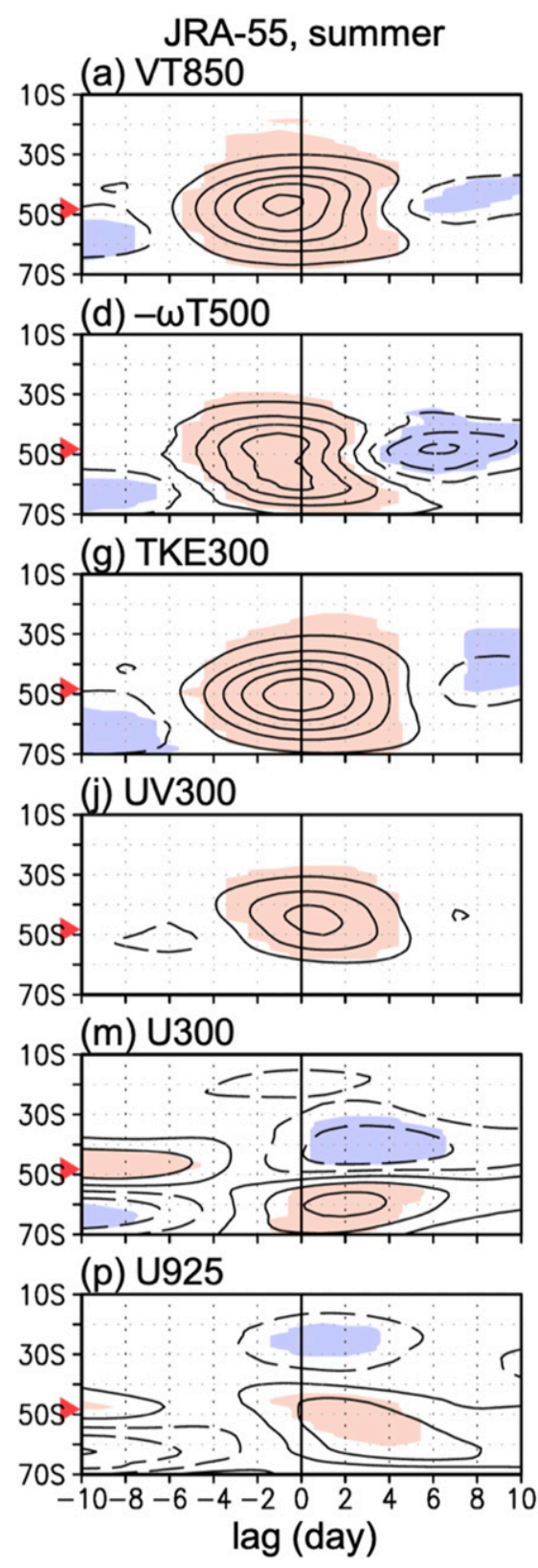
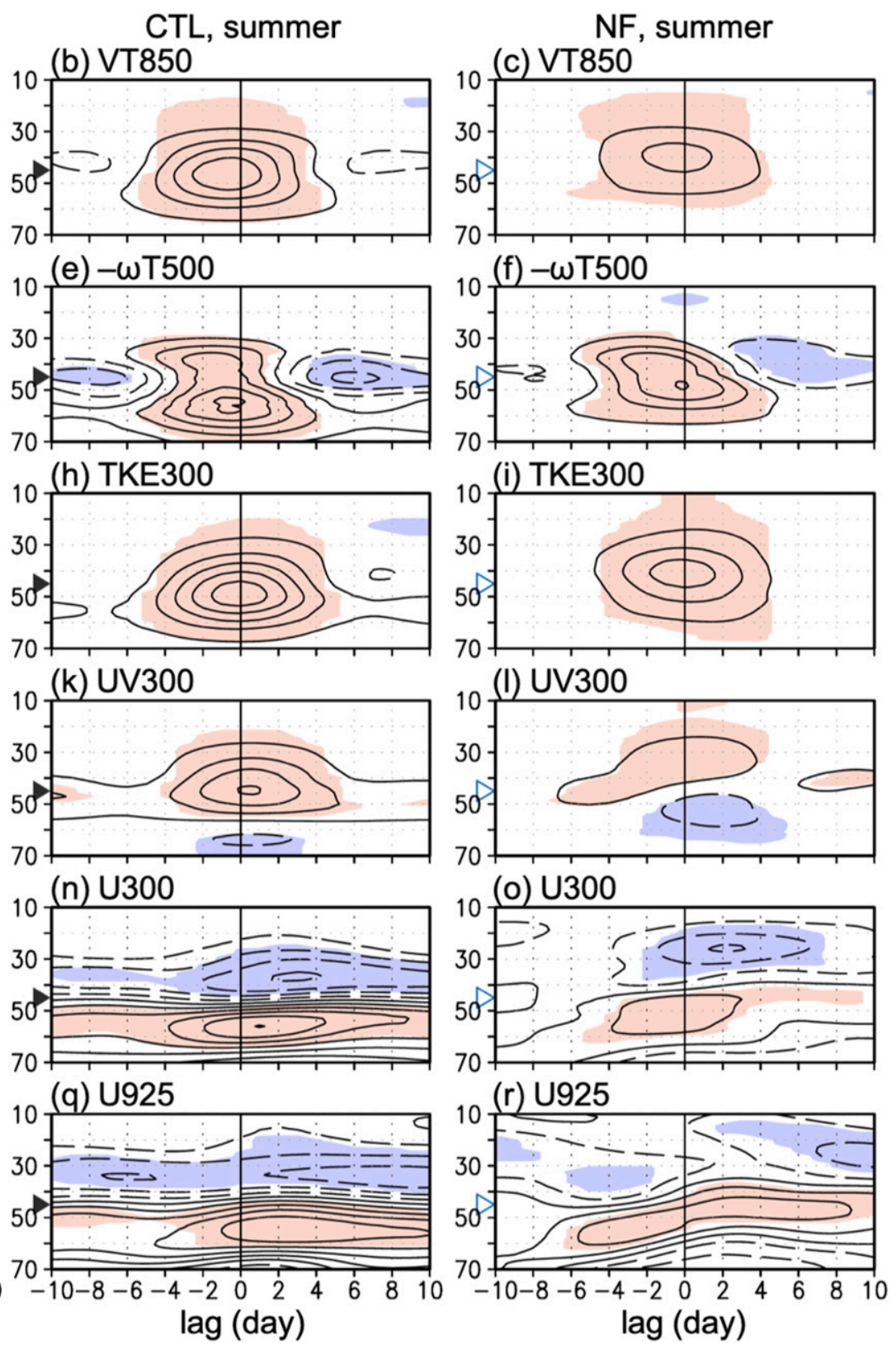

FIG. 7. Lag-latitude sections of anomalous (a) 850-hPa poleward $\left[v^{\prime} T^{\prime}\right]$, (d) 500-hPa [- $\left.\omega^{\prime} T^{\prime}\right]$, (g) 300-hPa [TKE], (j) 300-hPa poleward $\left[u^{\prime} v^{\prime}\right],(\mathrm{m}) 300-\mathrm{hPa}[u]$, and (p) 925-hPa [u], based on JRA-55 for the summertime SH. (b),(e),(h),(k),(n),(q) As in (a), (d), (h), (j),(m), and (p), respectively, but for the summer hemisphere of the CTL experiment. (c),(f),(i),(l),(o), (r) As in (b), (e), (h), (k), (n), and (q), respectively, but for the NF experiment. Each panel represents typical evolution of anomalies of a particular variable during the positive phase of BAM obtained as linear regression against the BAM index with a given lag. Positive lags represent anomalies lagging behind the BAM index. Contours are drawn for $\pm 0.3, \pm 0.9, \pm 1.5, \ldots\left(\mathrm{K} \mathrm{m} \mathrm{s}^{-1}\right)$ in (a) $-(\mathrm{c}), \pm 0.003, \pm 0.009, \pm 0.015, \ldots\left(\mathrm{K} \mathrm{Pa} \mathrm{s}^{-1}\right)$ in $(\mathrm{d})-(\mathrm{f}), \pm 4, \pm 12$, $\pm 20, \ldots\left(\mathrm{m}^{2} \mathrm{~s}^{-2}\right)$ in $(\mathrm{g})-(\mathrm{i}), \pm 2, \pm 6, \pm 10, \ldots\left(\mathrm{m}^{2} \mathrm{~s}^{-2}\right)$ in $(\mathrm{j})-(\mathrm{l}), \pm 0.2, \pm 0.6, \pm 1.0, \ldots\left(\mathrm{m} \mathrm{s}^{-1}\right)$ in $(\mathrm{m})-(\mathrm{o})$, and $\pm 0.1, \pm 0.3, \pm 0.5, \ldots(\mathrm{m} \mathrm{s})$ in (p)-(r). Dashed lines are for negative anomalies. Red and blue shading shows the $95 \%$ confidence level of the corresponding positive and negative correlations, respectively. Triangles and cusps are as in Fig. 2.

peak of the $[u]$ anomalies that represent the slight meridional shift of the PFJ with some projection onto the SAM-associated $[u]$ anomalies. This result suggests a nonnegligible relationship between the BAM defined for transient disturbances and the SAM, which was not pointed out by TW14. To verify this, we have defined the SAM index for each experiment or the reanalysis by applying an EOF analysis to low-frequency $[u]$ anomalies within the same domain as used for defining the BAM index. Figures 11a-d compare the meridional profiles of $300-\mathrm{hPa}[u]$ anomalies associated with the BAM and SAM. 

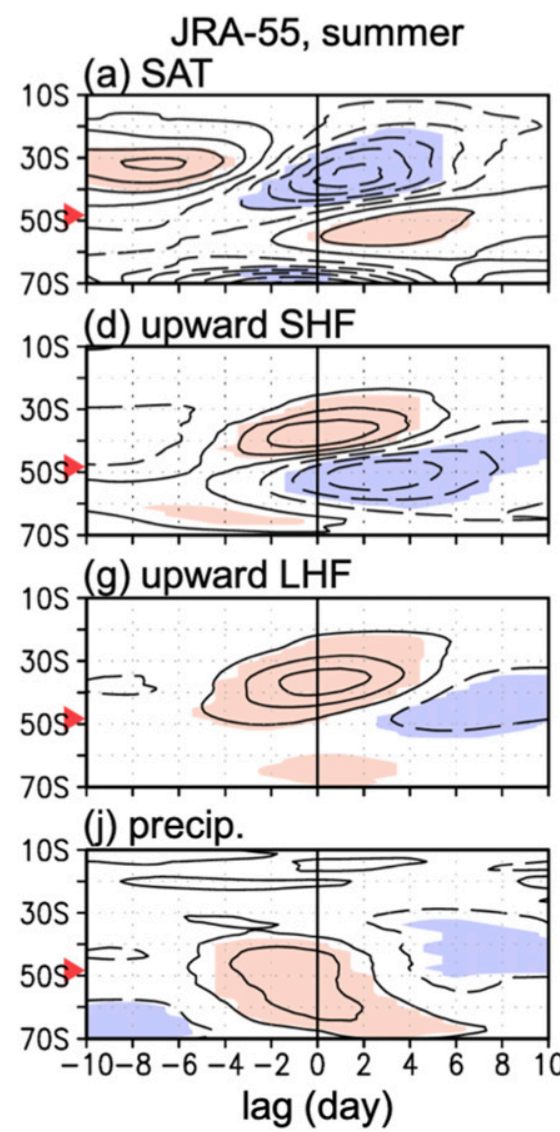

CTL, summer

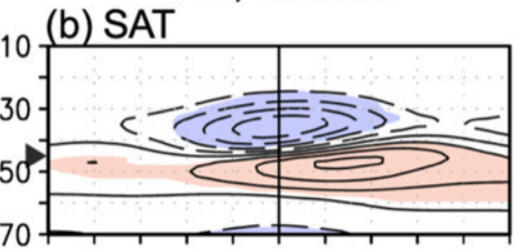

(e) upward SHF

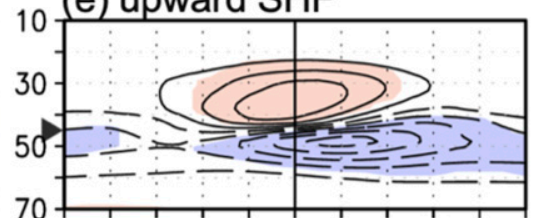

(h) upward LHF

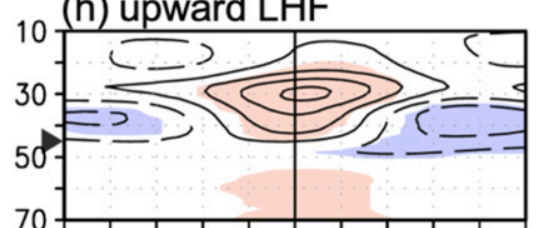

(k) precip.

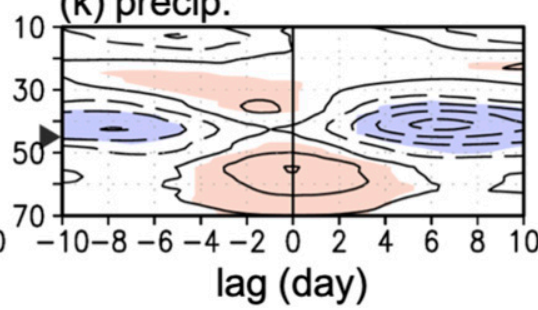

(c) SAT

$\mathrm{NF}$, summer

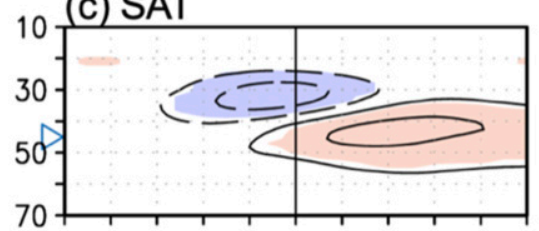

(d) upward SHF

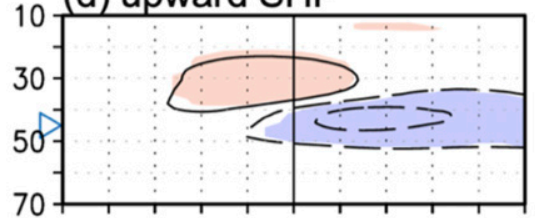

(i) upward LHF

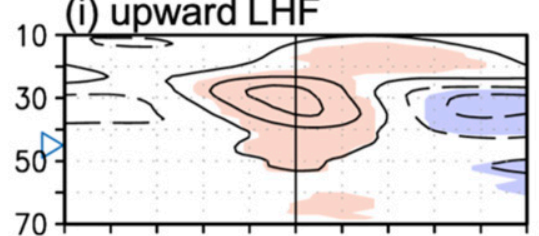

(I) precip.

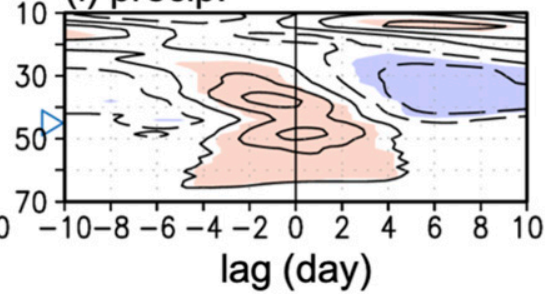

FIG. 8. As in Fig. 7, but for BAM-associated zonal-mean anomalies in (a)-(c) 2-m temperature (SAT), (d)-(f) sensible heat flux (SHF) and (g)-(i) latent heat flux (LHF), both from the ocean, and (j)-(l) precipitation. Contours are drawn for $\pm 0.01, \pm 0.03, \pm 0.05, \ldots$ (K) in (a)-(c), $\pm 0.2, \pm 0.6, \pm 1.0, \ldots\left(\mathrm{W} \mathrm{m}^{-2}\right)$ in (d)-(f), $\pm 1, \pm 3, \pm 5, \ldots\left(\mathrm{W} \mathrm{m}^{-2}\right)$ in $(\mathrm{g})-(\mathrm{i})$, and $\pm 0.04, \pm 0.12, \pm 0.20, \ldots\left(\mathrm{mm} \mathrm{day}^{-1}\right)$ in (j)-(l).

In the reanalysis and the two experiments and regardless of the season, the BAM-associated $[u]$ anomalies exhibit a certain projection onto those with the SAM, while the former is substantially weaker than the latter. In the reanalysis, for example, the BAM anomalies in $[u]$ are only $\sim 20 \%$ in magnitude of the corresponding SAM anomalies for each season, whereas the corresponding fractions are around $35 \%$ and $45 \%$ for the CTL and NF experiments, respectively. In the summer hemisphere (Figs. 11a,c), the $[u]$ anomalies associated with the BAM and SAM share very similar latitudinal profiles with respect to their maxima, minima, and nodes. The similarity is reduced, however, in the winter hemisphere (Figs. 11b,d), but the two $[u]$ anomalies still overlap poleward of the climatological PFJ axis.

In Figs. 11e-h, the meridional profiles of $300-\mathrm{hPa}$ [TKE] anomalies are compared between the SAM and BAM in the same manner as in Figs. 11a-d. As pointed out by TW14, the [TKE] anomalies are much stronger for the BAM as a manifestation of the pulsing of storm track activity (Figs. 11e,f). Except in the summer hemisphere of the NF experiment, the poleward PFJ shift with the positive SAM is preceded by $\sim 1$ day by the peak of poleward extension or shift of the storm track (Figs. 11g,h; the evolution of the SAM anomalies is not shown) rather than its pulsing. Nevertheless, the [TKE] anomalies associated with the BAM and SAM considerably overlap on the poleward side of the climatological-mean storm track (Figs. 11e-h).

To confirm the relationship suggested above between the BAM and SAM anomalies, we calculate lag-correlation and coherence between the BAM and SAM indices, the former defined for transient disturbances. Their cross-spectra and power spectra necessary to calculate their squared coherence have been obtained in the same manner as described below in section 7. As evident in Figs. 12a and 12b, the correlation coefficient between the BAM and SAM indices tends to maximize when the latter is lagged by 1-3 days, which is common in both the CTL and NF experiments as well as in the reanalysis regardless of the season. The peak correlation is significant in each experiment and reanalysis, although somewhat overestimated in the model. In the reanalysis, their coherence squared is found to exhibit a significant peak $(>+0.2)$ for the 30-50-day period in each of the seasons (not shown), which is reproduced only in the winter hemisphere of the NF experiment. Otherwise, their coherence squared in the model is significant at longer periods (not shown). Although the BAM explains only $4 \%$ of the SAM variability, their phase relationships are 

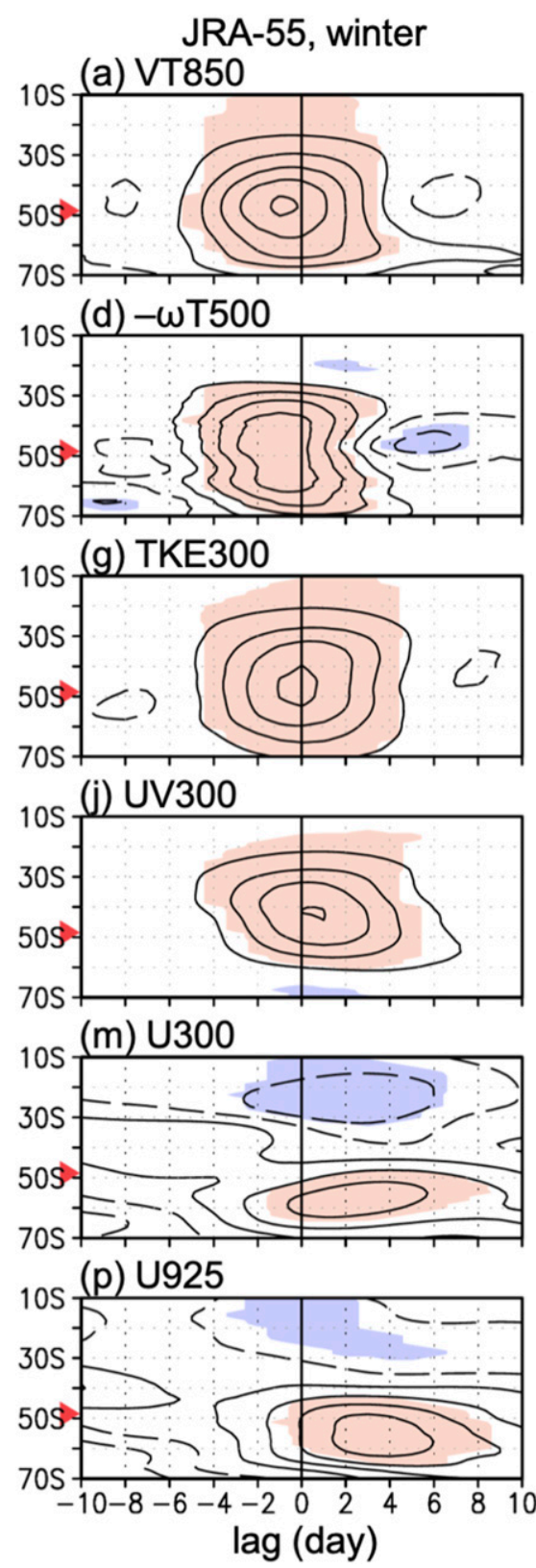

(b) VT 850

CTL, winter
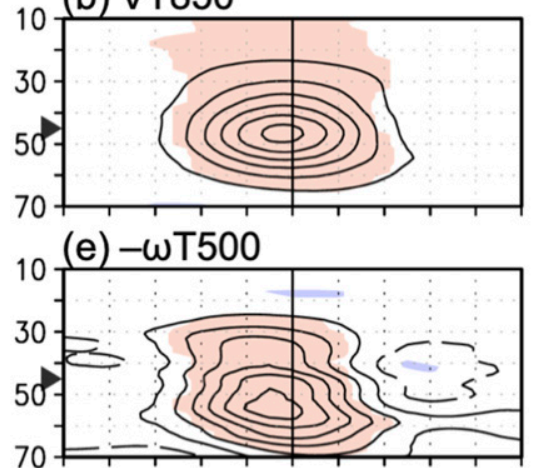

(h) TKE300

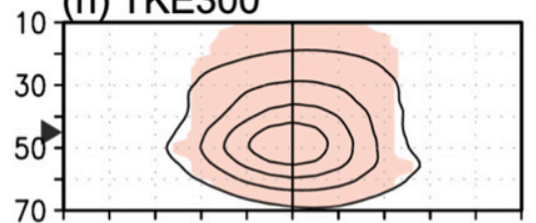

(k) UV300

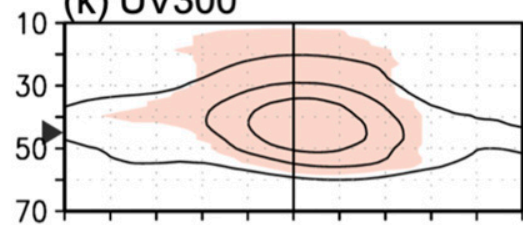

(n) U300

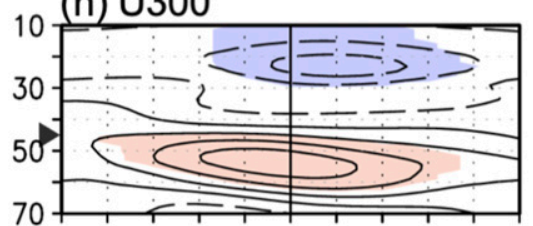

(q) U925

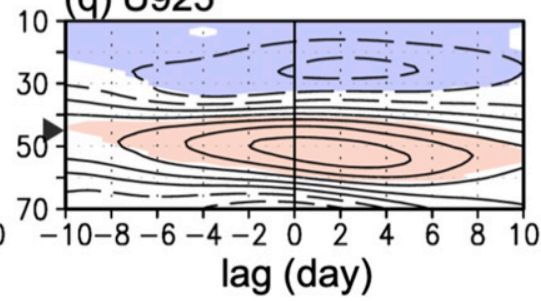

(c) VT850

$\mathrm{NF}$, winter
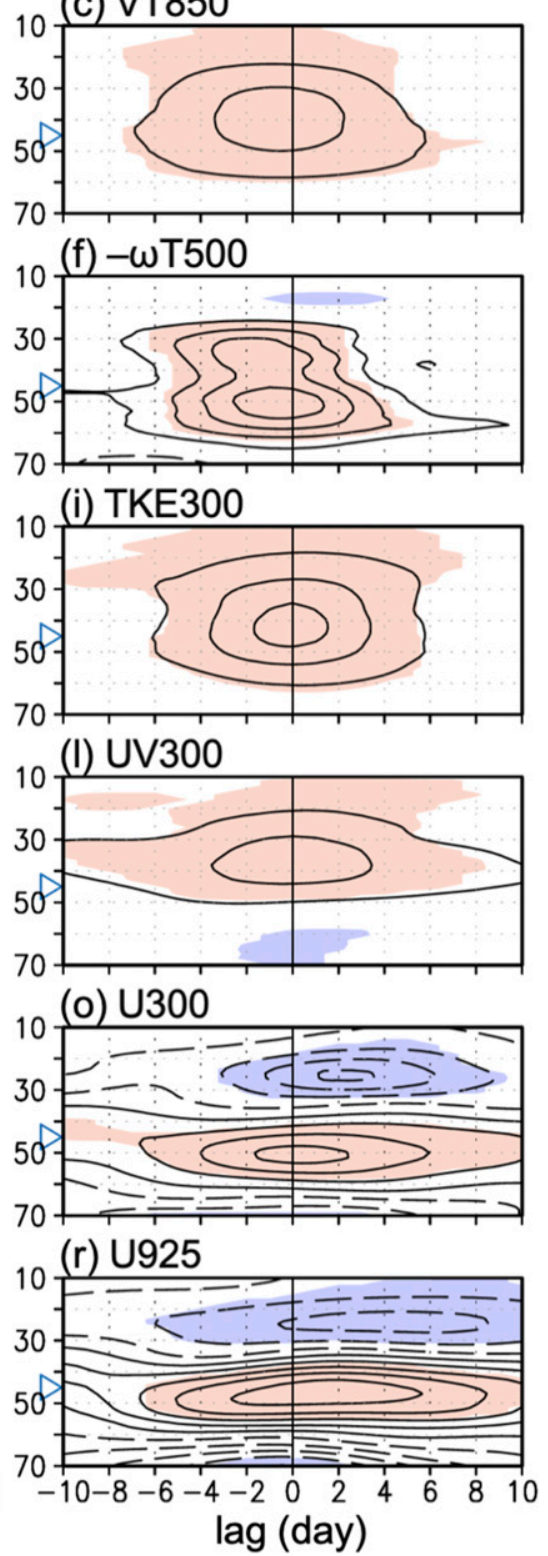

FIG. 9. As in Fig. 7, but for (left) the wintertime SH based on the JRA-55, and the winter hemispheres of the (center) CTL and (right) NF experiments.

consistent with the aforementioned lag-correlation analyses, confirming that the BAM can help maintain the SAM.

\section{Periodicity of the BAM index}

This section examines whether the quasi-periodic behavior of the BAM found by TW14 and TB14 can be verified in our datasets by computing power spectra of our BAM indices based on subweekly disturbances in the following manner. A daily BAM index for a given hemisphere of a particular aquaplanet experiment was first divided into 256-day segments with 128-day overlaps between the adjacent segments. Each segment was then tapered with a split cosine bell window with tapering of $10 \%$ of the whole data before being exposed to a 5 day running mean. The spectra obtained for all the segments were finally averaged to obtain a single spectrum with at least 168 degrees of freedom. Likewise, the daily BAM indices based on the JRA-55 were also divided into 256-day segments, but separately for austral warm (from 9 September to 21 or 22 May) and cold (from 11 March to 21 November) seasons. Power spectra were then calculated separately for each season in the same manner as for the aquaplanet experiments. 

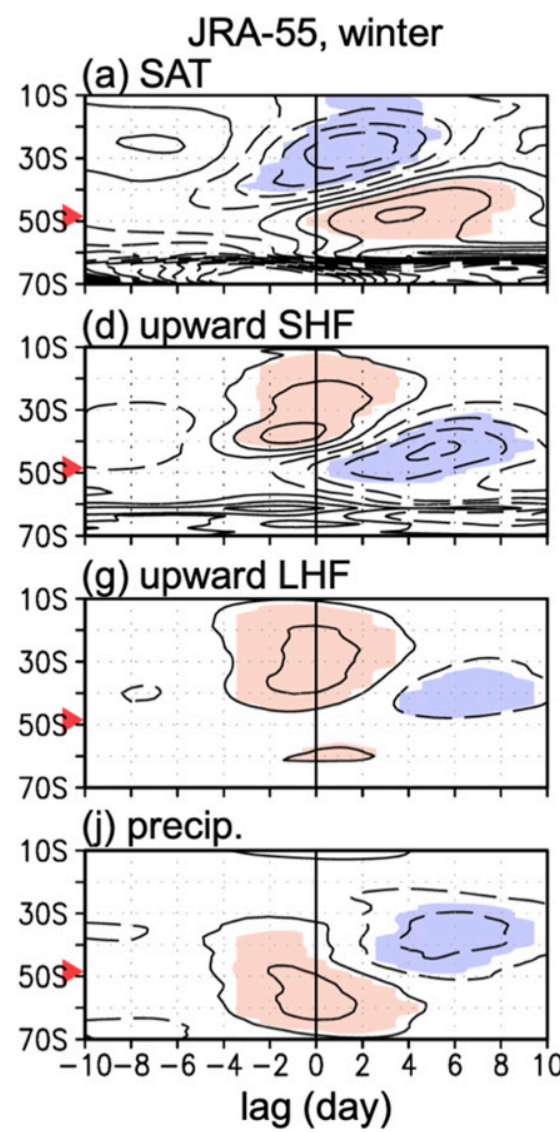

(b) SAT CTL, winter

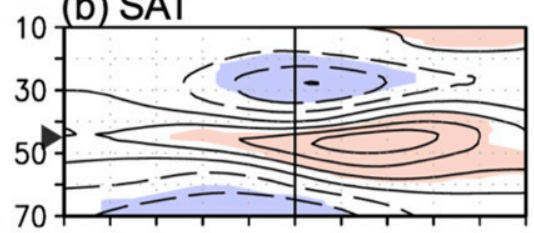

(e) upward SHF

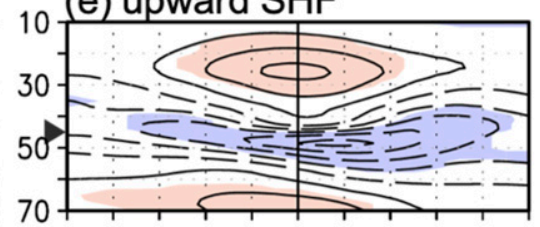

(h) upward LHF

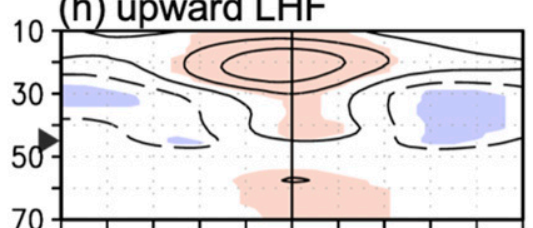

(k) precip.

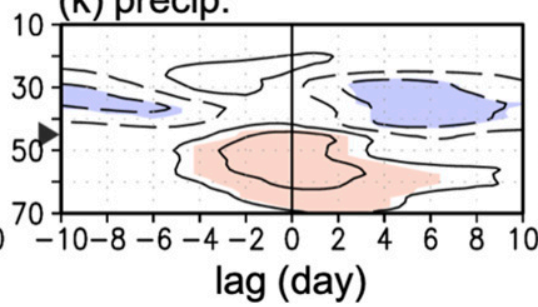

(c) SAT

$\mathrm{NF}$, winter

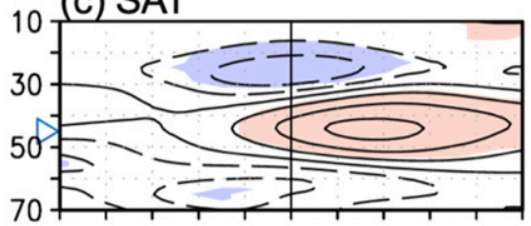

(d) upward SHF
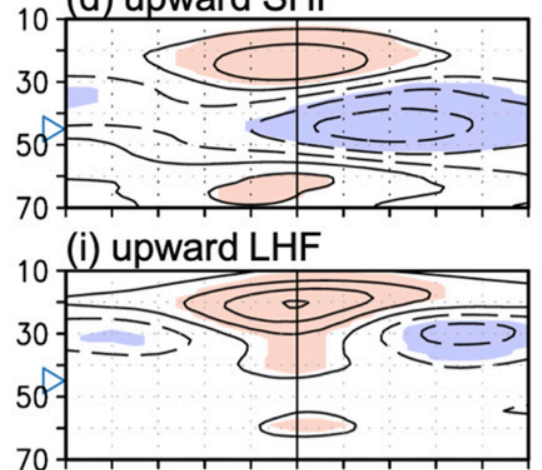

(I) precip.

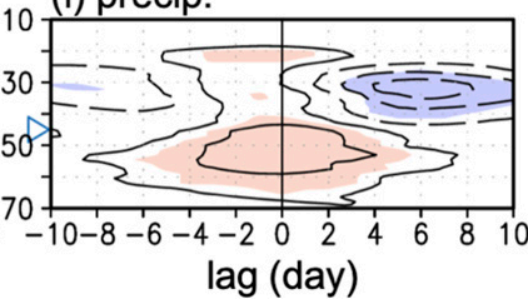

FIG. 10. As in Fig. 8, but for (left) the wintertime SH based on the JRA-55, and the winter hemispheres of the (center) CTL and (right) NF experiments.

It should be noted that the spectra shown below are based on the unnormalized BAM indices and therefore include the information of their variances.

Figures $13 \mathrm{a}$ and $13 \mathrm{~b}$ show the observed BAM spectra defined for transient disturbances, characterized by marginally significant peaks at periods of 25-30 days and 30-40 days for the austral warm and cold seasons, respectively. This result seems consistent with the observed quasi-periodic behavior of the BAM, as found by TW14 and TB14, while suggesting its slight seasonality. Meanwhile, the BAM spectrum for the CTL experiment (Figs. 13c-f) exhibits no distinct peak. In the NF experiment, a spectral peak is found at periods of 20-30 days, although the spectral powers are substantially reduced in the absence of the oceanic frontal zone. Nevertheless, the spectra for the simulated BAM deviate significantly from the corresponding red spectra for periods longer than 20 days.

Although the quasi-periodic behavior of the BAM is hinted at as above in both the reanalysis and aquaplanet experiments, the corresponding spectral peaks are less distinct than those found in the previous studies (e.g., TW14). This indistinctness is probably because our BAM indices are based only on subweekly transient disturbances. To confirm this, we repeated the same spectral analysis as above but for the BAM indices defined as in the previous studies. Specifically, we calculated
[EKE] based on instantaneous local deviations from the zonal means, in place of [TKE], before the EOF analysis. As shown in Figs. 14a and 14b, the power spectrum of the BAM index thus calculated from the JRA-55 data for each of the SH seasons exhibits a distinct peak at periods of 20-30 days, in good agreement with TW14, TB14, Wang and Nakamura (2015, 2016), and Boljka et al. (2018). The spectral peak is more evident for the austral warm season than for the cold season, as pointed out by Wang and Nakamura (2016). Well-defined spectral peaks are also found in the corresponding spectra for the CTL and NF experiments, although the peak is less distinct for the summer hemisphere of the NF experiment. The spectral peaks of the BAM index based on [EKE] in the NF experiment suggest that the quasi-periodic behavior of the BAM arises mainly from internal atmospheric dynamics rather than from the influence of the oceanic frontal zone.

It should be noted that the BAM indices derived from [TKE] (Fig. 13) and [EKE] (Fig. 14) are not strongly correlated. Their simultaneous correlation is between +0.4 and +0.6 in each of the experiments and reanalysis data, and no lead-lag relationships are evident (not shown). Therefore, their modest correlation is likely due to the contribution from low-frequency quasi-stationary disturbances, which is included only in [EKE]. Our definition of 

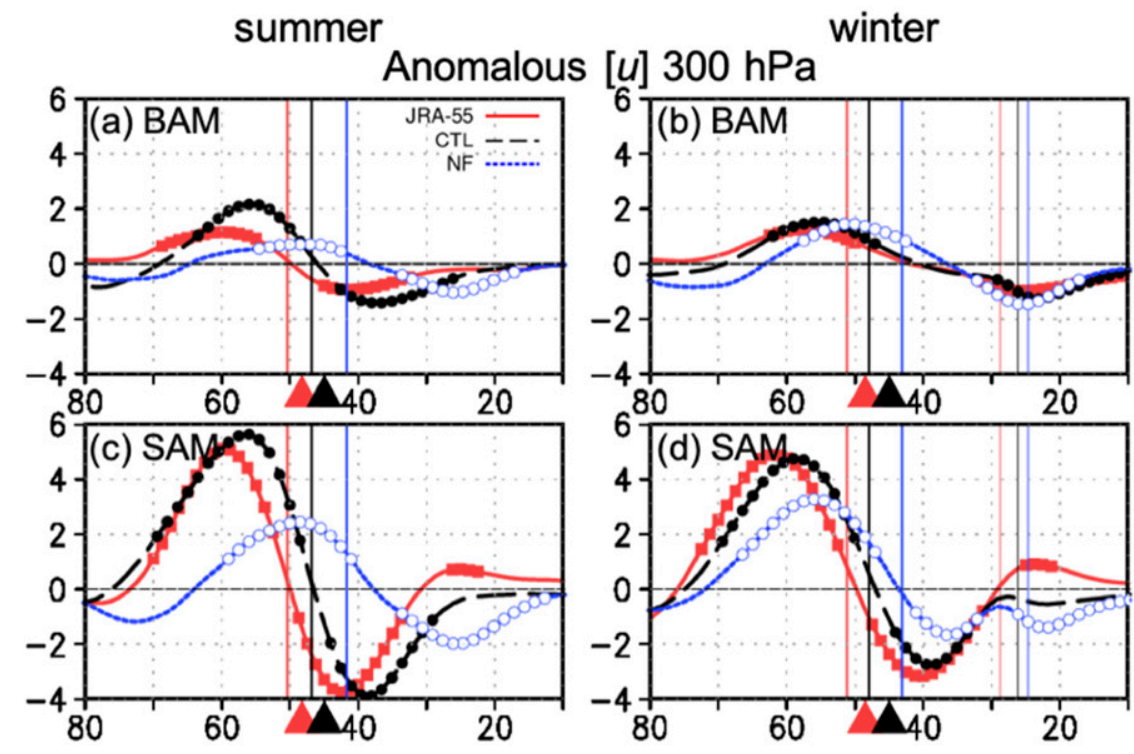

Anomalous [TKE] $300 \mathrm{hPa}$
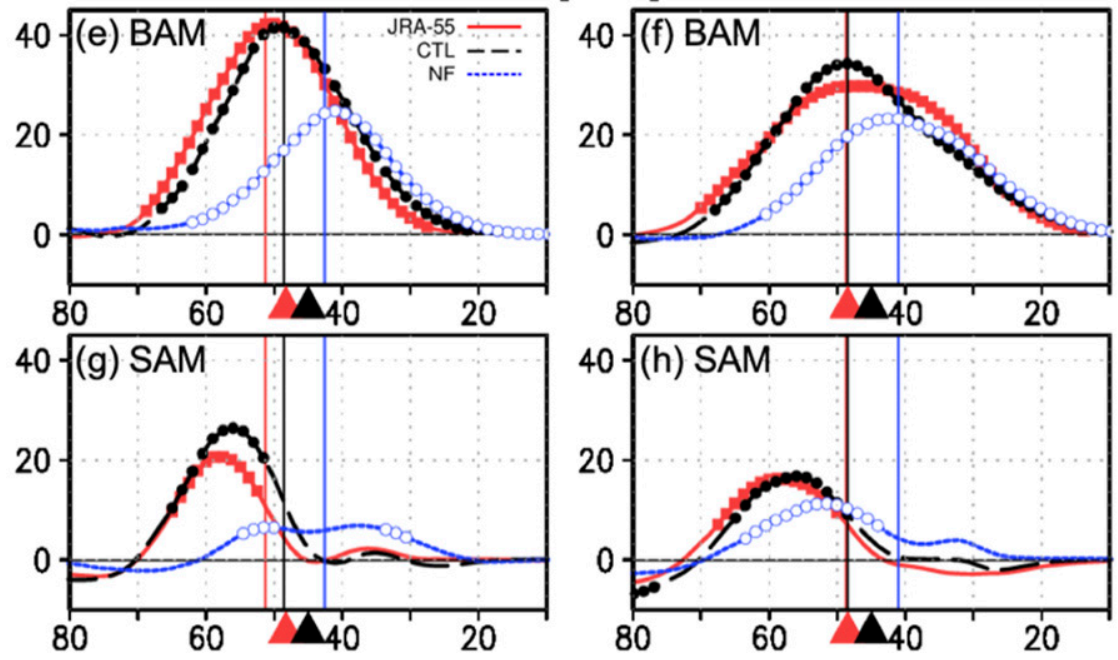

FIG. 11. Latitudinal profiles of anomalous $300-\mathrm{hPa}[u]\left(\mathrm{m} \mathrm{s}^{-1}\right)$ regressed on the (a),(b) BAM and (c),(d) SAM indices for the summer hemisphere in (a) and (c) and winter hemisphere in (b) and (d). Thick and thin vertical lines represent the latitude of the climatological PFJ (maximum $850-\mathrm{hPa}[u]$ for the summer and winter hemispheres, respectively) and STJ (peaks of 300-hPa $[u]$ for the winter hemisphere), respectively. (e)-(h) As in (a)-(d), respectively, but for anomalous $300-\mathrm{hPa}$ [TKE]. Vertical lines represent the latitudinal positions of climatological storm track axes detected as peaks of 300-hPa [TKE]. Red, black, and blue colors indicate the results for the SH based on JRA-55, the CTL and NF experiments, respectively. Dots indicate the corresponding anomalies with significant correlations at the $95 \%$ confidence level. Each anomaly lags behind the corresponding index by +2 days in (a) and (b), 0 days in (c) and (d), 0 days in (e) and (f), and -1 day in (g) and (h). Red and black triangles indicate the zonally averaged latitudes of the oceanic frontal zone observed in the $\mathrm{SH}$ and prescribed in the meridional SST profile for the CTL experiment, respectively.

the BAM based on [TKE] can effectively extract the contribution of subweekly migratory disturbances so as to clarify the time evolution of the BAM in relation to the typical life cycle of baroclinic disturbances and their feedback onto the zonal-mean westerlies. We have shown, however, that the quasi-periodic behavior of the BAM cannot be well extracted when derived from [TKE]. These results suggest that the quasi-periodicity of the $\mathrm{BAM}$ is generated not only by subweekly transient disturbances but also by low-frequency quasi-stationary disturbances and 

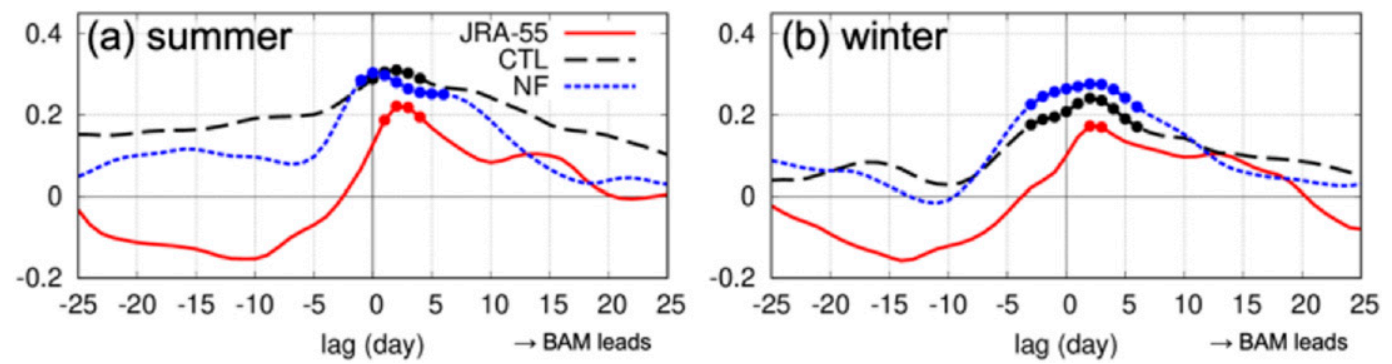

FIG. 12. Cross-correlation function between the BAM and SAM indices for (a) summertime and (b) wintertime SH based on the JRA-55 (solid line) and the CTL (dashed line) and NF (dotted line) experiments. Positive lags mean that the BAM index leads the SAM index. Dots indicate statistically significant correlations with the $95 \%$ confidence level.

possibly by their interactions as well. In addition, those quasi-stationary disturbances may also contribute to the spectral differences in the summertime [EKE]-based BAM between the CTL and NF experiments, especially for periods longer than $\sim 50$ days (Figs. 14c,f). In fact, Ogawa et al. (2015) showed that the oceanic frontal zone acts to energize not only subweekly transient but quasi-stationary disturbances. The similarity in the quasi-periodicity of the [EKE]-based BAM reproduced in both the CTL and NF experiments (Figs. 14c-f) suggests that the influence of the oceanic frontal zone on transient disturbances is not necessarily an essential mechanism for the quasi-periodicity of the BAM.

\section{Discussion and concluding remarks}

In recent years, the importance of a midlatitude oceanic frontal zone has been shown not only for the climatologicalmean field, including the storm track and PFJ, but also for such low-frequency climate variability as the SAM. In the present study, the corresponding impacts for the BAM are assessed through a comparison between aquaplanet AGCM experiments with and without the realistic frontal SST gradients. Though idealized, the aquaplanet experiment with the midlatitude frontal SST gradient well reproduces the BAM variability observed in the $\mathrm{SH}$ that represents the pulsing of midlatitude storm track activity measured by KE and poleward heat flux both associated with subweekly transient disturbances. The elimination of the frontal SST gradient yields marked weakening of the BAM-associated anomalies in storm track activity and the equatorward shift of the BAM signatures. These modifications in the BAM variability exhibit strong correspondence to those in the climatological storm track activity, which can be attributed to the marked reduction of nearsurface baroclinicity maintained by differential heat supply across the midlatitude oceanic frontal zone (Nakamura et al. 2008; Sampe et al. 2010; Hotta and Nakamura 2011). In other words, the frontal zone amplifies and anchors the BAM variability by energizing baroclinic disturbances through maintaining near-surface baroclinicity and thereby augmenting the climatological-mean storm track activity. Specifically, anomalous upward SHF from the ocean associated with the BAM around the oceanic frontal zone acts to restore meridional near-surface SAT gradient modulated by anomalous poleward heat flux associated with transient disturbances and thereby maintain the BAM variability. In our experiment with the distinct frontal SST gradient, this restoring effect measured as the BAM-associated anomalous SHF gradient is more than twice as strong as in the other experiment without the frontal SST gradient.

Although substantially weaker, the BAM signatures simulated in our model experiment without frontal SST gradient still represent the pulsing of the climatological-mean storm track activity. In other words, the elimination of the oceanic frontal zone yields no fundamental differences in the dynamical characteristics of the BAM. Thus, our experiments indicate that the BAM is driven essentially by atmospheric internal dynamics rather than by the influence of the oceanic frontal zone.

Unlike in previous studies (e.g., TW14), we analyzed the BAM-associated modulations in the activity of subweekly transient disturbances, which has led to the elucidation of the dynamical characteristics of the BAM as a manifestation of a typical life cycle of baroclinic disturbances. We have revealed that the BAM-modulated storm track activity alters momentum flux associated with transient disturbances, acting to induce zonal wind anomalies that have a significant projection onto those associated with the SAM. Although these BAM-induced wind anomalies account only for a small fraction of the SAM variance, this new finding suggests that the BAM can help maintain the SAM through modifying westerly momentum transport associated with transient disturbances. It has been shown that the SAM owes its existence to barotropic forcing by transient disturbances for maintaining PFJ and its meridional migration (e.g., Thompson and Wallace 2000; Lorenz and Hartmann 2001; Sampe et al. 2013). Our study suggests that the BAM-modulated subweekly disturbances may also contribute to the SAM variability. It remains unsolved why the SAM and BAM variations become uncorrelated if one extracts the BAM variability from all eddy activities defined as departures from the zonal means. In fact, our analysis based on the JRA-55 data has revealed that the BAM index derived from [EKE] exhibits no significant correlation with the SAM index (not shown), which confirms the finding by TW14. For 

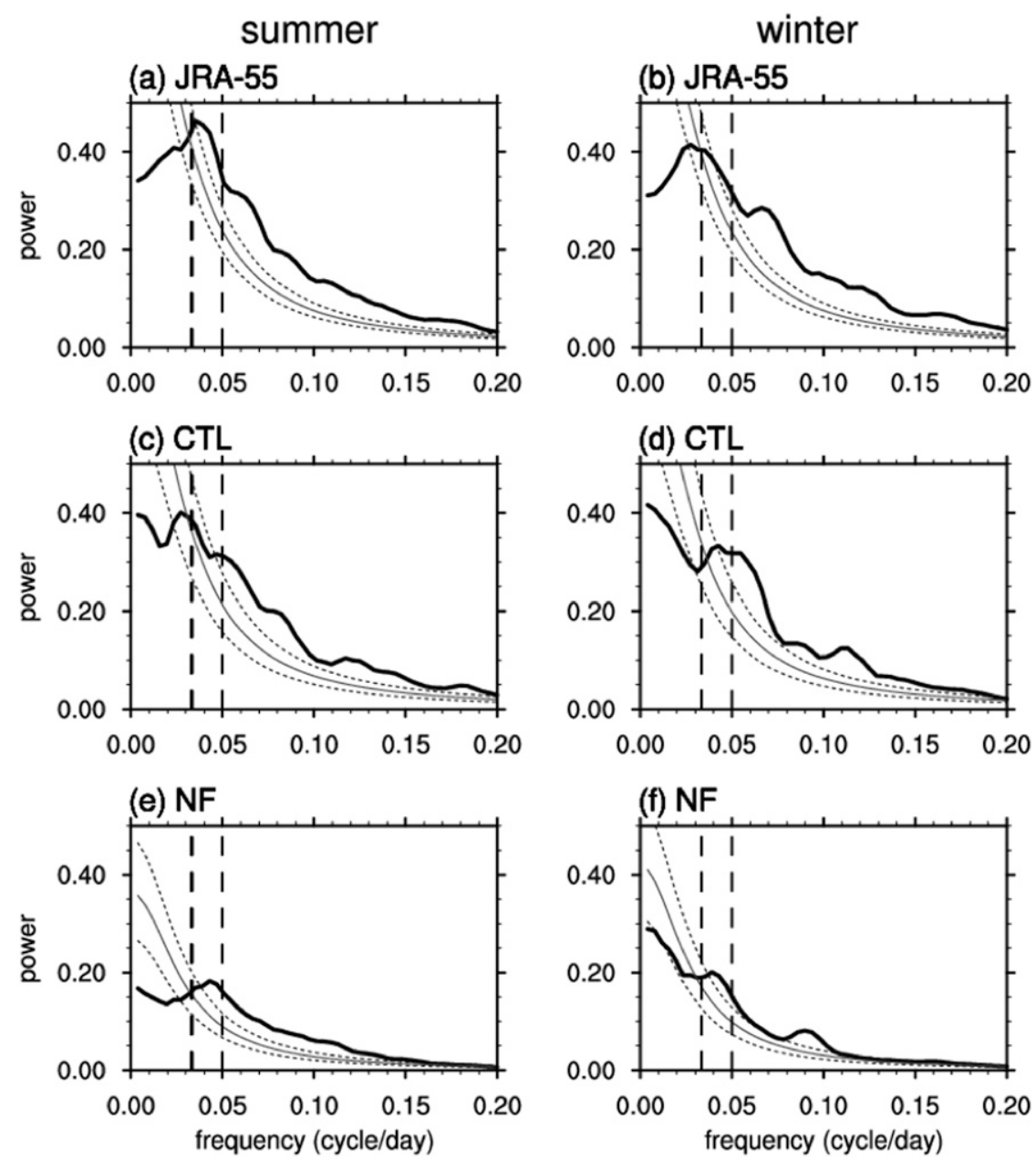

FIG. 13. Power spectra of the BAM indices (black line) observed in the SH (a) warm and (b) cold seasons and simulated for the (c) summer and (d) winter hemispheres in the CTL experiment. (e),(f) As in (c) and (d), respectively, but for the NF experiment. The spectra are calculated for the unnormalized BAM indices. Red noise curve (thin solid) and the corresponding curves showing the $99 \%$ confidence levels (thin dashed) are superimposed. Vertical dashed lines represent the periods of 20 and 30 days. See the text for details.

solving this issue and deepening our understanding of the quasi-periodic behavior of the BAM, assessing the contributions from low-frequency quasi-stationary disturbances to the BAM variability is helpful, although it is beyond the scope of the present study.

Owing to their idealized setting, our aquaplanet AGCM experiments are not designed for fully reproducing the BAM variability observed in the $\mathrm{SH}$ but rather for extracting its fundamental dynamics. For example, the SST field prescribed for our CTL experiment is zonally uniform and taken from its climatological field in the south Indian Ocean, where one of the most distinct frontal SST gradients is observed (Nakamura and Shimpo 2004; Nakamura et al. 2004). Thus, the influence of the oceanic frontal zone on the BAM activity revealed in this study should be regarded as its upper bound and therefore somewhat overestimated in our CTL experiment compared with its observational counterpart in the SH. The corresponding experiments with more modest differences in the meridional SST gradient will be performed in our future study to obtain additional insights into the BAM sensitivity to the strength of the oceanic frontal zone. Investigation of the zonal asymmetries in the BAM signatures over the $\mathrm{SH}$ will also be conducted in our future study. In fact, Ogawa et al. (2016) demonstrated that the observed SAM behavior depends on the latitudinal position of the oceanic frontal zone over each of the ocean basins, leading to zonal asymmetries in the SAM signature.

Furthermore, prescribing the fixed SST profiles for our aquaplanet AGCM experiments is also unrealistic. In reality, both SST and surface westerlies vary on interannual and longer time scales, for example, under the remote influence from the tropics. Furthermore, many previous studies have investigated the relationship between SST variability and midlatitude atmosphere (e.g., Czaja and Frankignoul 2002; Taguchi et al. 2012; 

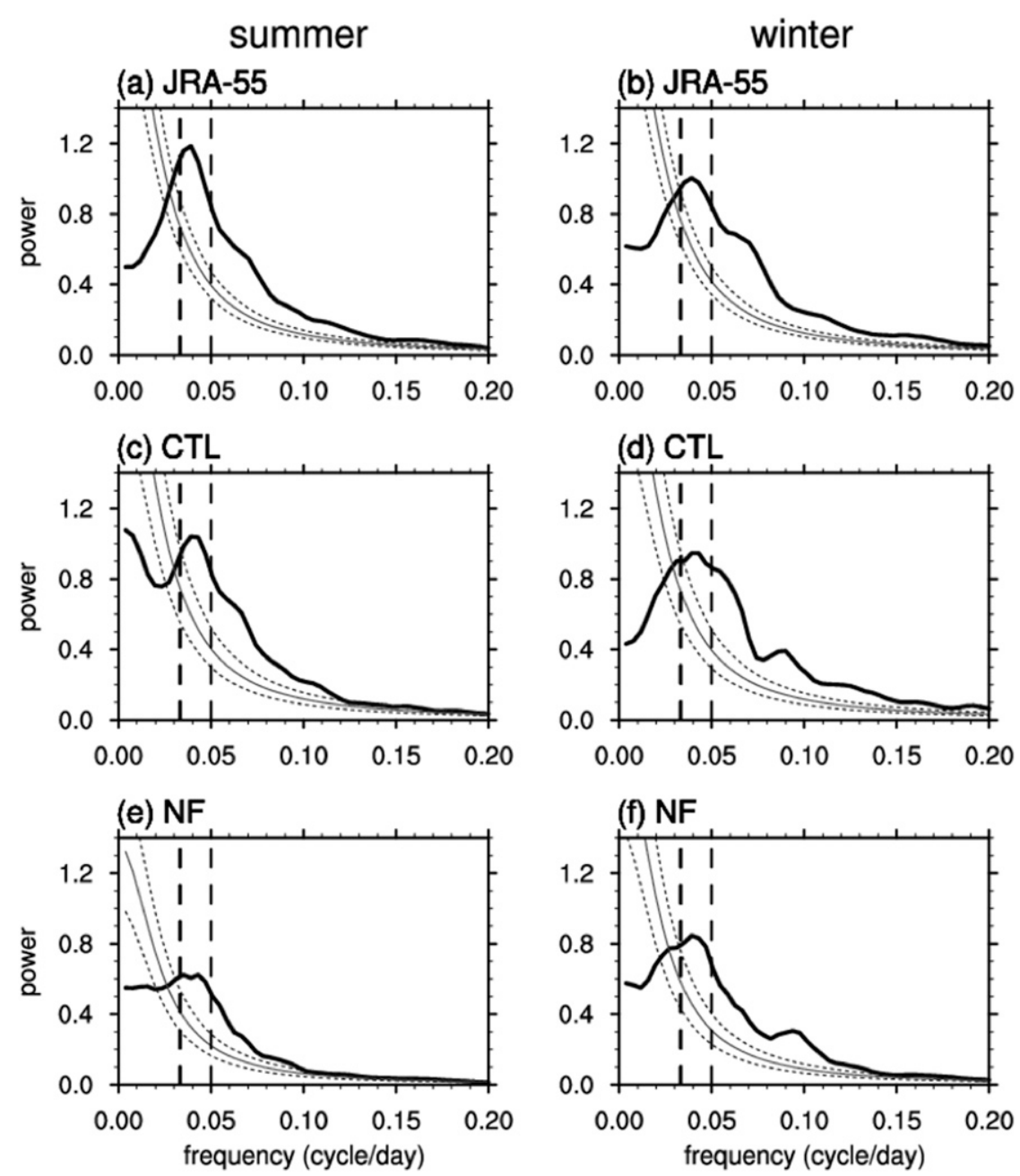

FIG. 14. As in Fig. 13, but for the BAM indices derived from eddies in the same manner as in TW14 and other previous studies.

Zhang et al. 2018). Although the SST differences observed in the extratropical $\mathrm{SH}$ between the positive and negative phases of the BAM are quite small (not shown), any possible impacts of SST variability on the BAM will be addressed in our future study. Besides, the effect of sea ice may not be negligible, as the wintertime BAM signature in near-surface meridional heat flux associated with transient disturbances is maximized around $65^{\circ} \mathrm{S}$ (Fig. 3b). The impacts of sea ice on the BAM cannot be assessed in our aquaplanet experiments and will be addressed in a different framework in our future study. We believe, however, that the characteristics of the BAM simulated in our CTL experiment, including its structure and time evolution, reflect those observed in the SH. Therefore, we argue that essential dynamics of the BAM derived from migratory baroclinic disturbances is extracted in our aquaplanet experiment.

Following previous studies, including TW14, TB14, Wang and Nakamura $(2015,2016)$, and Boljka et al. (2018), we used zonal-mean statistics of storm track activity and the background state in recognition of the high annularity of the BAM.
One should keep in mind, however, that the BAM variability is a manifestation of eastward propagating transient disturbances along the storm track (TW14). The zonal averaging automatically eliminates zonally asymmetric processes, including downstream development of baroclinic disturbances. In our future study, investigating the modulated behavior of individual synoptic-scale disturbances typical for the onset, peak, and decay stages of the positive and negative phases of the BAM will provide deeper insights into the BAM dynamics with implications for the local influence of the BAM and improvement of its predictability.

Acknowledgments. The authors sincerely thank Prof. David W. J. Thompson and two anonymous reviewers for reading our manuscript carefully and giving us sound criticism and constructive comments. This study is supported in part by the Japan Society for the Promotion of Science (JSPS) through Grants-in-Aid for Scientific Research JP19H05702 (on Innovative Areas 6102), JP18H01278, and 20H01970; by 
the Japanese Ministry of Education, Culture, Sports, Science and Technology (MEXT) through the Arctic Challenge for Sustainability II (ArCS-II) Program; by the Japanese Ministry of Environment through the Environment Research and Technology Development Fund JPMEERF20192004; and by the Japan Science and Technology Agency through Belmont Forum CRA "InterDec" and COI-NEXT JPMJPF2013. The JRA-55 reanalysis dataset has been provided through the Data Consortium of the Japan Meteorological Agency, and the NOAA Optimum Interpolation SST data (OISST) through the NOAA-CIRES Climate Diagnostics Center, Boulder, Colorado, from their website (http://www.cdc.noaa.gov/). The Grid Analysis and Display System (GrADS), NCAR Command Language (NCL), and Gnuplot were used for drawing figures.

\section{REFERENCES}

Blackmon, M. L., 1976: A climatological spectral study of the $500 \mathrm{mb}$ geopotential height of the Northern Hemisphere. J. Atmos. Sci., 33, 1607-1623, https://doi.org/10.1175/15200469(1976)033<1607:ACSSOT>2.0.CO;2.

—, J. M. Wallace, N.-C. Lau, and S. L. Mullen, 1977: An observational study of the Northern Hemisphere wintertime circulation. J. Atmos. Sci., 34, 1040-1053, https://doi.org/ 10.1175/1520-0469(1977)034<1040:AOSOTN > 2.0.CO;2.

__, Y.-H. Lee, J. M. Wallace, and H.-H. Hsu, 1984: Time evolution of 500-mb height fluctuations with long, intermediate and short time scales as deduced from lag-correlation analysis. J. Atmos. Sci., 41, 981-991, https://doi.org/10.1175/15200469(1984)041<0981:TVOMHF>2.0.CO;2.

Boljka, L., T. G. Shepherd, and M. Blackburn, 2018: On the coupling between barotropic and baroclinic modes of extratropical atmospheric variability. J. Atmos. Sci., 75, 1853-1871, https://doi.org/10.1175/JAS-D-17-0370.1.

Charney, J. G., 1947: The dynamics of long waves in a baroclinic westerly current. J. Meteor., 4, 136-162, https://doi.org/10.1175/ 1520-0469(1947)004<0136:TDOLWI > 2.0.CO;2.

Czaja, A., and C. Frankignoul, 2002: Observed impact of Atlantic SST anomalies on the North Atlantic Oscillation. J. Climate, 15, 606-623, https://doi.org/10.1175/1520-0442(2002)015<0606: OIOASA $>2.0 . \mathrm{CO} ; 2$.

Eady, E., 1949: Long waves and cyclone waves. Tellus, 1, 33-52, https://doi.org/10.3402/tellusa.v1i3.8507.

Enomoto, T., A. Kuwano-Yoshida, N. Komori, and W. Ohfuchi, 2008: Description of AFES 2: Improvements for highresolution and coupled simulations. High Resolution Numerical Modelling of the Atmosphere and Ocean, K. Hamilton and W. Ohfuchi, Eds., Springer, 77-97, https://doi.org/10.1007/ 978-0-387-49791-4_5..

Hotta, D., and H. Nakamura, 2011: On the significance of sensible heat supply from the ocean in the maintenance of mean baroclinicity along storm tracks. J. Climate, 24, 3377-3401, https:// doi.org/10.1175/2010JCLI3910.1.

Kobayashi, S., and Coauthors, 2015: The JRA-55 Reanalysis: General specifications and basic characteristics. J. Meteor. Soc. Japan, 93, 5-48, https://doi.org/10.2151/jmsj.2015-001.

Kuwano-Yoshida, A., T. Enomoto, and W. Ohfuchi, 2010: An improved PDF cloud scheme for climate simulations. Quart. J. Roy. Meteor. Soc., 136, 1583-1597, https://doi.org/10.1002/qj.660.

Lorenz, D. J., and D. L. Hartmann, 2001: Eddy-zonal flow feedback in the Southern Hemisphere. J. Atmos. Sci., 58,
3312-3327, https://doi.org/10.1175/1520-0469(2001)058<3312: EZFFIT>2.0.CO;2.

Nakamura, H., and A. Shimpo, 2004: Seasonal variations in the Southern Hemisphere storm tracks and jet streams as revealed in a reanalysis data set. J. Climate, 17, 1828-1844, https:// doi.org/10.1175/1520-0442(2004)017<1828:SVITSH>2.0.CO;2. , T. Sampe, Y. Tanimoto, and A. Shimpo, 2004: Observed associations among storm tracks, jet streams and midlatitude oceanic fronts. Earth's Climate: The Ocean-Atmosphere Interaction, Geophys. Monogr., Vol. 147, Amer. Geophys. Union, 329-345, https://doi.org/10.1029/147GM18.

- — - A. Goto, W. Ohfuchi, and S.-P. Xie, 2008: On the importance of midlatitude oceanic frontal zones for the mean state and dominant variability in the tropospheric circulation. Geophys. Res. Lett., 35, L15709, https://doi.org/ 10.1029/2008GL034010.

Nonaka, M., H. Nakamura, B. Taguchi, N. Komori, A. KuwanoYoshida, and K. Takaya, 2009: Air-sea heat exchanges characteristic of a prominent midlatitude oceanic front in the south Indian Ocean as simulated in a high-resolution coupled GCM. J. Climate, 22, 6515-6535, https://doi.org/10.1175/ 2009JCLI2960.1.

North, G. R., T. L. Bell, R. F. Cahalan, and F. J. Moeng, 1982: Sampling errors in the estimation of empirical orthogonal functions. Mon. Wea. Rev., 110, 699-706, https://doi.org/ 10.1175/1520-0493(1982)110<0699:SEITEO > 2.0.CO;2.

Ogawa, F., H. Nakamura, K. Nishii, T. Miyasaka, and A. KuwanoYoshida, 2012: Dependence of the climatological axial latitudes of the tropospheric westerlies and storm tracks on the latitude of an extratropical oceanic front. Geophys. Res. Lett., 39, L05804, https://doi.org/10.1029/2011GL049922.

_- N. E. Omrani, K. Nishii, H. Nakamura, and N. Keenlyside, 2015: Ozone-induced climate change propped up by the Southern Hemisphere oceanic front. Geophys. Res. Lett., 42, 10 056-10 063, https://doi.org/10.1002/2015GL066538.

—, H. Nakamura, K. Nishii, T. Miyasaka, and A. KuwanoYoshida, 2016: Importance of midlatitude oceanic frontal zones for the annular mode variability: Interbasin differences in the southern annular mode signature. J. Climate, 29, 61796199, https://doi.org/10.1175/JCLI-D-15-0885.1.

Ohfuchi, W., H. Sasaki, Y. Masumoto, and H. Nakamura, 2007: "Virtual" atmospheric and oceanic circulations in the Earth Simulator. Bull. Amer. Meteor. Soc., 88, 861-866, https://doi.org/ 10.1175/BAMS-88-6-861.

Reynolds, R. W., T. M. Smith, C. Liu, D. B. Chelton, K. S. Casey, and M. G. Schlax, 2007: Daily high-resolution-blended analyses for sea surface temperature. J. Climate, 20, 5473-5496, https://doi.org/10.1175/2007JCLI1824.1.

Sampe, T., H. Nakamura, A. Goto, and W. Ohfuchi, 2010: Significance of a midlatitude SST frontal zone in the formation of a storm track and an eddy-driven westerly jet. J. Climate, 23, 1793-1814, https://doi.org/10.1175/2009JCLI3163.1.

,$- \ldots$, and $\longrightarrow, 2013$ : Potential influence of a midlatitude oceanic frontal zone on the annular variability in the extratropical atmosphere as revealed by aqua-planet experiments. J. Meteor. Soc. Japan, 91A, 243-267, https://doi.org/10.2151/ jmsj.2013-A09.

Taguchi, B., H. Nakamura, M. Nonaka, and S.-P. Xie, 2009: Influences of the Kuroshio/Oyashio Extensions on air-sea heat exchanges and storm-track activity as revealed in regional atmospheric model simulations for the 2003/04 cold season. J. Climate, 22, 6536-6560, https://doi.org/10.1175/ 2009JCLI2910.1. 
,,,--- N. Komori, A. Kuwano-Yoshida, K. Takaya, and A. Goto, 2012: Seasonal evolution of atmospheric response to decadal SST anomalies in the North Pacific subarctic frontal zone: Observations and a coupled model simulation. J. Climate, 25, 111-139, https://doi.org/10.1175/JCLI-D-11-00046.1.

Thompson, D. W. J., and J. M. Wallace, 2000: Annular modes in the extratropical circulation. Part I: Month-to-month variability. J. Climate, 13, 1000-1016, https://doi.org/10.1175/15200442(2000)013<1000:AMITEC>2.0.CO;2.

— , and E. A. Barnes, 2014: Periodic variability in the large-scale Southern Hemisphere atmospheric circulation. Science, 343, 641-645, https://doi.org/10.1126/science. 1247660.

- and J. D. Woodworth, 2014: Barotropic and baroclinic annular variability in the Southern Hemisphere. J. Atmos. Sci. 71, 1480-1493, https://doi.org/10.1175/JAS-D-13-0185.1.
Wang, L., and N. Nakamura, 2015: Covariation of finite-amplitude wave activity and the zonal mean flow in the midlatitude troposphere: 1 . Theory and application to the Southern Hemisphere summer. Geophys. Res. Lett., 42, 8192-8200, https://doi.org/ 10.1002/2015GL065830.

—, and — 2016: Covariation of finite-amplitude wave activity and the zonal-mean flow in the midlatitude troposphere. Part II: Eddy forcing spectra and the periodic behavior in the Southern Hemisphere summer. J. Atmos. Sci., 73, 4731-4752, https://doi.org/10.1175/JAS-D-16-0091.1.

Zhang, L., B. Gan, L. Wu, W. Cai, and H. Ma, 2018: Seasonal dependence of coupling between storm tracks and sea surface temperature in the Southern Hemisphere midlatitudes: A statistical assessment. J. Climate, 31, 4055-4074, https://doi.org/ 10.1175/JCLI-D-17-0196.1. 